\title{
High-Speed Boundary-Layer Transition Induced by an Isolated Roughness Element
}

\author{
Michael A. Kegerise, Lewis R. Owens ${ }^{\dagger}$ and Rudolph A. King ${ }^{\ddagger}$ \\ Flow Physics and Control Branch, NASA Langley Research Center, Hampton, VA 23681
}

\begin{abstract}
Progress on an experimental effort to quantify the instability mechanisms associated with roughness-induced transition in a high-speed boundary layer is reported in this paper. To simulate the low-disturbance environment encountered during high-altitude flight, the experimental study was performed in the NASA-Langley Mach 3.5 Supersonic LowDisturbance Tunnel. A flat plate trip sizing study was performed first to identify the roughness height required to force transition. That study, which included transition onset measurements under both quiet and noisy freestream conditions, confirmed the sensitivity of roughness-induced transition to freestream disturbance levels. Surveys of the laminar boundary layer on a $7^{\circ}$ half-angle sharp-tipped cone were performed via hot-wire anemometry and pitot-pressure measurements. The measured mean mass-flux and Mach-number profiles agreed very well with computed mean-flow profiles. Finally, surveys of the boundary layer developing downstream of an isolated roughness element on the cone were performed. The measurements revealed an instability in the far wake of the roughness element that grows exponentially and has peak frequencies in the 150 to $250 \mathrm{kHz}$ range.
\end{abstract}

\section{Introduction}

R OUghness induced boundary-layer transition is of critical interest to the design and performance of many Rhypersonic vehicles. Whether the roughness is distributed or isolated, it tends to accelerate laminarturbulent transition, thereby increasing skin-friction drag on and aero-thermal heating to the vehicle. Isolated roughness, in particular, is of concern because it may promote transition earlier than what is expected due to the nominal distributed roughness on a vehicle. For example, boundary-layer transition on the Space Shuttle Orbiter during reentry is normally driven by the distributed roughness presented by the tiles of the thermal protection system (TPS) and generally occurs at Mach numbers less than $8 .{ }^{1}$ Isolated roughness in the form of protruding gap fillers, however, can promote transition at a significantly higher Mach number and the resulting elevated heating levels to the TPS may compromise vehicle safety during reentry. ${ }^{2}$ Alternatively, an isolated roughness is sometimes used to intentionally trip the boundary layer to turbulence. Such is the case in scramjet applications, where isolated roughness elements are employed to enhance fuel/air mixing in the engine by tripping the boundary layer on the vehicle forebody. ${ }^{3}$ In both cases, accurate prediction of transition onset from isolated roughness elements is desired.

The prediction of transition onset from isolated roughness is often based on correlations derived from ground based wind tunnel tests and flight-test data. ${ }^{4,5}$ This approach can be effective, provided that a given correlation is applied only to the vehicle or geometry for which it was developed. However, the uncertainty in the predicted transition location associated with transition correlations can be large - a fact that is problematic in the design of thermal protection systems for hypersonic vehicles. Another drawback to transition correlations is that many are based on isolated roughness data collected in conventional ground-test facilities, where the freestream noise levels are an order of magnitude higher than those observed in flight. ${ }^{6}$ Recent measurements in a Mach 6 quiet tunnel indicate that freestream noise has a significant impact on roughness induced boundary-layer transition. ${ }^{7-9}$ Most significantly, transition correlations do not provide any physical insight to the instability mechanisms that play a role in roughness induced boundary-layer transition.

\footnotetext{
${ }^{*}$ Research Scientist, M.S. 170. Senior Member AIAA.

${ }^{\dagger}$ Research Scientist, M.S. 170. Senior Member AIAA.

${ }^{\ddagger}$ Research Scientist, M.S. 170 .
} 
To move beyond simple roughness correlations and into the realm of transition prediction via physicsbased methodologies, a thorough understanding of the instability mechanisms is required. Therefore, we developed an experimental and computational research effort that has the specific goal of quantifying the instability mechanisms leading to transition from an isolated roughness element immersed in a high-speed compressible boundary layer. The primary geometry for this study is an isolated roughness element, with varying geometric parameters, placed on a flat plate with a sharp leading edge. Recently, Choudhari et $a l .{ }^{10}$ performed computational simulations of the experimental setup, which included computations of the mean flow over various roughness-element geometries and a spatial stability analysis of the computed mean flow in the far wake of the roughness element. The experiments for the present effort are aimed at quantitative boundary-layer measurements of the roughness-induced instabilities. These measurements include both spatial and temporal variations of the instabilities from the location of the isolated roughness element through breakdown to turbulence. As these measurements will be used to validate the computational simulations, considerable effort was focused on the reduction of measurement uncertainties. To simulate the low-disturbance environment encountered during high-altitude flight, the experimental study was performed in the Mach 3.5 Supersonic Low-Disturbance Tunnel (SLDT), which has freestream noise levels that are less than $0.1 \%$. The study of roughness induced transition mechanisms in this facility is relevant to hypersonic reentry bodies, such as the Shuttle Orbiter at high angle-of-attack, where the boundary layer edge Mach number is between 2 and 3, even for freestream Mach numbers of 25.

In this paper, we report on our progress towards the quantitative measurement of roughness-induced instabilities in a supersonic boundary layer. Two aspects of the experimental effort are presented. First, the details of the flat-plate model and associated hardware are presented, followed by a trip-sizing study that was performed on the flat plate to identify the roughness height required to force transition. The second aspect focuses on the details of the quantitative boundary-layer measurements. Although the primary geometry is the flat plate, the SLDT Mach 3.5 2-D quiet nozzle, in which the flat plate model is to be tested, was not available due to unexpected delays in polishing of the nozzle-contour blocks. In the meantime, we decided to develop the boundary-layer measurement techniques on a $7^{\circ}$ half-angle sharp-tipped cone model that was installed in the SLDT Mach 3.5 axisymmetric quiet nozzle. That model shares similar hardware with the flat-plate model and therefore, it was felt that issues vetted on the cone model would be to the benefit of forthcoming tests on the flat plate. In the following sections, the boundary-layer measurement techniques are discussed in general and then specific results obtained on the cone model are presented. Baseline (no roughness element) boundary-layer measurements on the cone model at zero angle of attack are presented and then compared to computations of the mean flow over the cone. Those results are followed by boundary layer measurements downstream of an isolated roughness element placed on the cone model.

\section{Experimental Details}

\section{II.A. Facility}

The experiments were conducted in the Supersonic Low-Disturbance Tunnel (SLDT) at NASA Langley Research Center. This "quiet" wind tunnel facility produces a Mach 3.5 freestream with RMS static pressure fluctuations, $\tilde{p}_{\infty}$, that are less than $0.1 \%$ of the mean static pressure, $\bar{p}_{\infty}$. Since boundarylayer transition is particularly sensitive to the disturbance environment, testing in a low-noise facility, such as the SLDT, is necessary to simulate transition in the low disturbance environment encountered during high-altitude flight. Details on the facility operation and performance characteristics are provided in Beckwith et al. ${ }^{11}$ and Chen,${ }^{12}$ so here we provide a brief overview of the facility.

The illustration in Fig. 1 shows the side and plan views of the Mach 3.5 two-dimensional rapidexpansion nozzle, as well as the boundaries of the

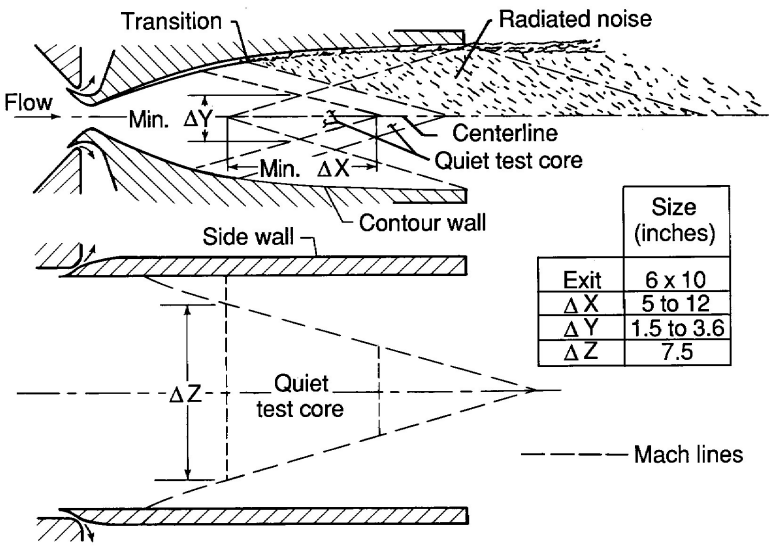

Figure 1. Mach 3.5 two-dimensional nozzle and quiet test core in the Supersonic Low-Disturbance Tunnel. quiet test core. The bleed slots, shown upstream of the nozzle throat, remove the boundary layer on the 

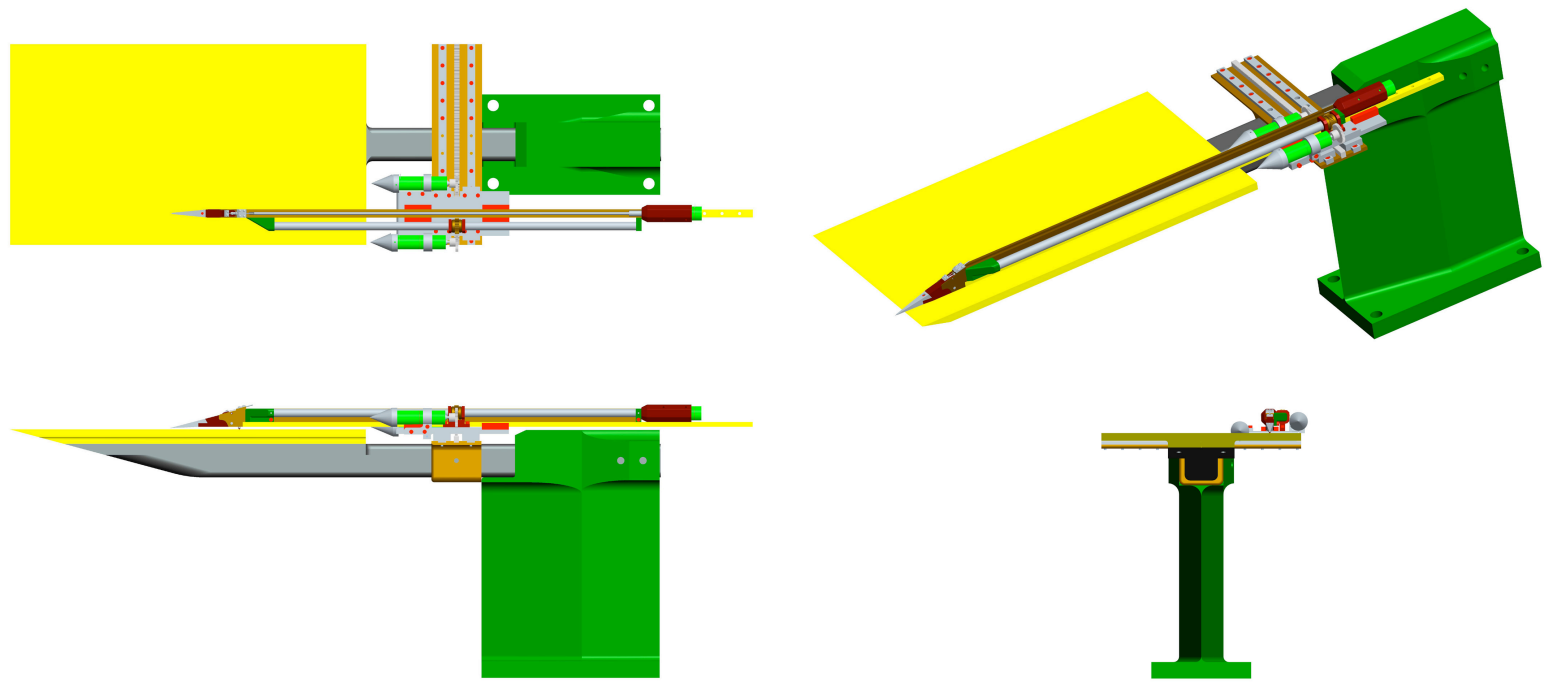

Figure 2. CAD model of the flat plate, support hardware (model sting and strut), and model traverse mechanism.

contour walls and side walls of the subsonic approach. Then, the laminar boundary layers evolving on the highly-polished nozzle-contour walls eventually transition, and at that point, high-intensity noise is radiated from the supersonic turbulent boundary layer eddies. These acoustic disturbances are propagated nearly parallel to Mach lines originating from the transition location to form the downstream boundary of the quiet test core. The upstream boundaries of the uniform quiet test core are determined by Mach lines originating at the upstream edge of the uniform Mach 3.5 flow. A typical range of lengths for the quiet test core, $\Delta X$, are shown in Fig. 1. Since transition on the nozzle contour walls moves upstream with increasing unit Reynolds number, the length of the quiet test core is a decreasing function of unit Reynolds number. The width of the quiet test core in the span-wise direction, $\Delta Z$, is determined by the nozzle width and Mach lines originating from the sidewalls at a location where the local Mach number is $\approx 2.5$. At that Mach number, acoustic radiation from the generally turbulent side wall boundary layers becomes significant. ${ }^{13,14}$ The quiet test core, as defined here, provides a flow region where wind-tunnel models can be tested in a low-noise environment (measured $\tilde{p}_{\infty} / \bar{p}_{\infty}$ is less than $0.1 \%$ ).

The SLDT can also be configured with a Mach 3.5 axisymmetric quiet nozzle that operates on the same general principles as the two-dimensional nozzle. Chen et al. ${ }^{15}$ provide details on the design and performance of the axisymmetric nozzle.

\section{II.B. Flat-Plate Model}

A CAD model of the flat plate, support hardware (model sting and strut), and model traverse mechanism is shown in Fig. 2. The flat plate was machined from 15-5 stainless steel and is $406.4 \mathrm{~mm}$ long, $228.6 \mathrm{~mm}$ wide, and $8.79 \mathrm{~mm}$ thick. The leading edge has a $15^{\circ}$ bevel and a measured leading-edge thickness of 0.05 $\mathrm{mm}$. The maximum interference-free length of the plate, as determined by disturbances propagating at the Mach angle $\left(16.6^{\circ}\right.$ at Mach 3.5) from the leading-edge corners, is $383 \mathrm{~mm}$. The top surface of the flat plate was lapped and polished to a roughness level of $0.0254 \mu \mathrm{m}$ RMS and had no visible scratches at 3 times magnification. Measurements of the model surface flatness indicated a maximum $2.5 \mu \mathrm{m}$ deviation over the entire plate dimension. The flat plate is instrumented with 15 type-K thermocouples, positioned along the model centerline, for measurement of the surface temperature. The first thermocouple is positioned $38.1 \mathrm{~mm}$ from the leading edge, with subsequent thermocouples spaced in $25.4 \mathrm{~mm}$ increments. For the measurements presented in this article, the leading edge of the flat plate model was placed at the upstream boundary of the quiet test core to maximize the length of quiet flow extending over the model.

A 3-axis traverse mechanism, attached to the model sting, was designed to survey the flat plate boundary layer. Motion along the $z$-axis (across the model span) is produced with a rack and pinion, driven by a miniature stepper motor, and a pair of linear ball-bearing guides. The travel in the $z$-direction is limited to 


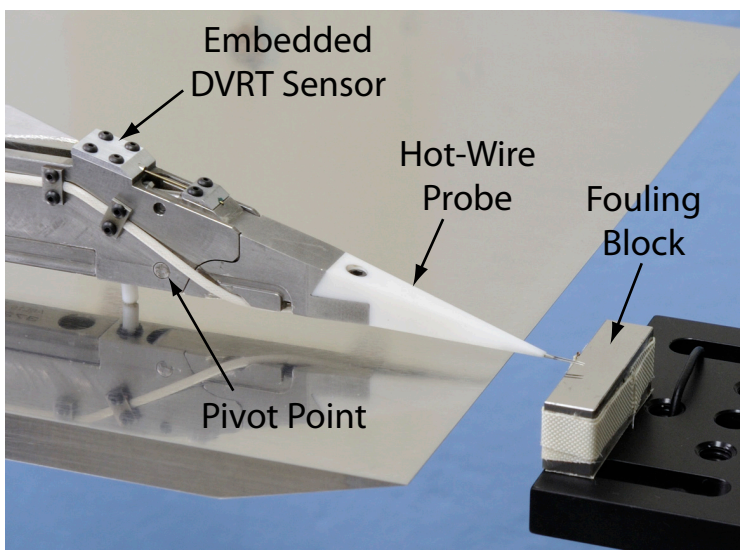

(a) Setup for DVRT sensor calibration.

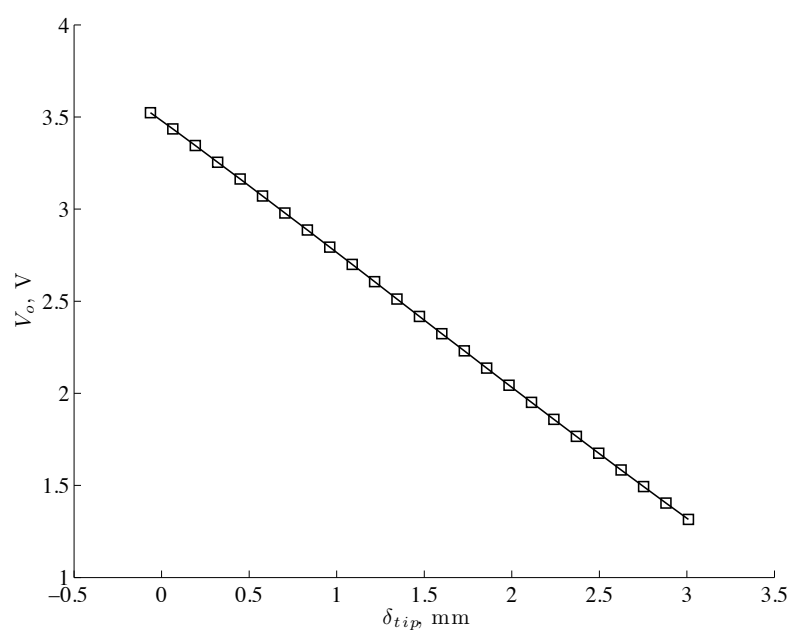

(b) DVRT sensor calibration for hot-wire probe.

Figure 3. DVRT sensor calibration.

$\pm 76.2 \mathrm{~mm}$ about the model centerline and the $z$-axis resolution, as measured by a Faro Xi laser tracker, is $0.127 \mathrm{~mm}$. Motion along the $x$-axis (along the model length) is produced with a miniature stepper motor that drives a nut on a precision lead screw. The travel in the $x$-direction extends $12.7 \mathrm{~mm}$ upstream of the model leading edge and ends at $355.6 \mathrm{~mm}$ downstream of the leading edge. The $x$-axis resolution, as measured by the laser tracker, is $4 \mu \mathrm{m}$. Motion along the $y$-axis (across the boundary-layer thickness) is achieved by pivoting the probe head (hot-wire or pitot probe) about a fixed pivot point. The motion about the pivot point is driven by a lead screw that is coupled to a miniature stepper motor. The travel in the $y$-direction extends from the wall to approximately $3 \mathrm{~mm}$ above the wall. A micro-miniature DVRT (differential variable reluctance transducer) displacement sensor, which measures the translational motion of the probe head about the pivot point, provides feedback to accurately locate the probe tip in the boundary layer. That sensor was calibrated by moving the probe tip down until it touched a gage block and then measuring the sensor output voltage (see Fig. 3a for the setup). This procedure was performed for a range of gage-block positions that were set with a motorized traverse to which the gage block was attached. The result is a linear relationship between the DVRT output voltage and the probe-tip deflection (see Fig. 3b for an example calibration). Note that the deflection defined here is positive in the direction toward the model surface. From the calibration data, the $y$-axis resolution was found to be approximately $2.4 \mu \mathrm{m}$.

\section{II.C. Boundary-Layer Measurements}

The primary objective of the current experiment is to measure the development of instability waves downstream of an isolated roughness element in a supersonic flat plate boundary layer. Prior to these measurements, however, the 2-D quiet nozzle was sent out for polishing to improve the quiet-flow performance. Due to unexpected delays in that effort, the nozzle was unavailable for boundary-layer measurements on the flat-plate model. In the meantime, we developed our boundary layer measurement techniques on a $7^{\circ}$ half-angle cone model that was tested in the SLDT with the Mach 3.5 axisymmetric quiet nozzle. That model is $381 \mathrm{~mm}$ in length, has a sharp tip (0.05 mm bluntness), and has a highly polished surface finish. It also has a similar sting-mounted traverse design and shares boundary-layer probes with the flat-plate model. Further details on the cone model will be presented in a forthcoming paper. ${ }^{16}$ Here, we discuss common issues related to boundary-layer measurements on these models, and in the results section, we will present boundary-layer measurements on the cone model with and without an isolated roughness element.

Boundary-layer measurements on these models are particularly difficult given the small scale and the resulting thin boundary layers $(\delta \sim 1 \mathrm{~mm})$. Accurate measurements require a high spatial resolution in the wall-normal direction and a frequency response in excess of $100 \mathrm{kHz}$; therefore, hot-wire anemometry was chosen as the primary instrument. However, when performing quantitative hot-wire measurements in a thin supersonic boundary layer, several issues must be addressed. First, the hot-wire probe body must be designed to minimize mean-flow distortion. Second, exceptional care must be taken to achieve accurate wall- 
normal positioning of the probe in the boundary layer. This is particularly important when boundary-layer measurements are compared to computational results. Third, the sensitivity of the hot-wire to multiple flow variables (mass flux and total temperature) must be accounted for in the hot-wire calibration.

To address the issue of mean-flow distortion, particular attention was paid to the design of the hot-wire probe body. Starting with the wedge-body design of Matlis, ${ }^{17}$ a computational simulation of the hot-wire probe, immersed in a zero-pressure-gradient laminar boundary layer, was performed to evaluate the probe interference (see Owens and Kegerise ${ }^{18}$ for details). Probe bodies with different wedge-tip span widths, wedge-tip radii, and prong lengths were simulated to determine the probe geometry that yielded minimal interference. A photo of the final hot-wire probe design, based on these CFD simulations, is shown in Fig. 4. For the chosen design, the simulations indicated a worst-case mass-flux uncertainty of $2 \%$ due to probe interference.

To set the wall-normal positions of the hot-wire probe during a boundary-layer survey, the following procedure was used. First, the hot-wire probe tip was moved downward, in $6 \mu \mathrm{m}$ increments, until the hot-wire prongs touched the model surface. Contact with the model surface was sensed with a switch circuit that stopped the traverse once contact was made. The calibrated DVRT displacement sensor was then used to determine the probe-tip deflection, $\delta_{\text {wall }}$, associated with the model-surface touch. With that known, the desired wall-normal positions, $y$, were set by moving the probe head up, in $2.4 \mu \mathrm{m}$ increments, until the DVRT sensor indicated $\delta_{t i p}=\delta_{\text {wall }}-y$ for each position. Due to deflection of the traverse arm, however, the relative distance between the traverse arm and the model surface was found to be a function of the streamwise location. It follows that $\delta_{\text {wall }}$ was also a function of location, and therefore, it was necessary to repeat the prong-model touch wherever a boundary-layer survey was performed. By following that procedure, we were able to set the desired wall-normal positions during a boundary-layer survey to within $\pm 6.5 \mu \mathrm{m}$.

The hot-wire probe was operated in the constanttemperature (CTA) mode with a symmetric bridge, which affords a high frequency response and low bridge noise. ${ }^{19}$ Furthermore, the CTA was operated at a high overheat ratio $\left(\tau=\left(T_{w}-\eta T_{o}\right) / T_{o} \sim 1\right.$, where $T_{w}$ is the wire temperature, $T_{o}$ is the total temperature, and $\eta$ is the recovery factor) to produce an output primarily sensitive to mass-flux fluctuations, $(\rho U)^{\prime}$, and total-temperature fluctuations, $T_{o}^{\prime}$, can be neglected. ${ }^{20}$ In that case, the main advantage of the CTA is that continuous mass-flux time series can be measured. The hot-wire sensors were platinum-plated tungsten, with a $3.8 \mu \mathrm{m}$ diameter and $1 \mathrm{~mm}$ nominal length $(\ell / d>250)$, welded to the ends of the hot-wire prongs. The wires were always mounted with slack to avoid strain-gauging effects. A typical hot-

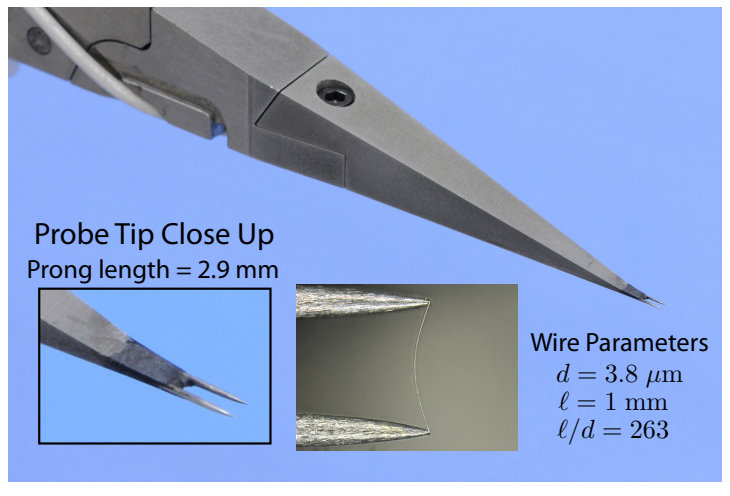

Figure 4. Hot-wire probe used for boundary-layer measurements. wire sensor installation is shown in Fig. 4. The frequency response of the hot-wire, which was optimized via square-wave injection when the sensor was positioned outside the boundary layer, was typically $270 \mathrm{kHz}$.

The hot-wires were calibrated in the NASA-Langley Probe Calibration Tunnel (PCT), ${ }^{21}$ which was configured with a Mach 3.5 axisymmetric nozzle. There, the hot-wire probe was positioned on the nozzle centerline and exposed to a mass-flux range that covers the range expected during a boundary-layer survey. Example mass-flux calibrations for two different total temperatures are shown in Fig. 5a. For that data, the nominal overheat ratio was 0.9 at a total temperature of $297 \mathrm{~K}$. During the hot-wire calibrations, the total temperature was maintained to within $\pm 1 \mathrm{~K}$ of the desired nominal value (see Fig. 5b for examples). Mass-flux calibration data are generally fit to a curve of the form:

$$
E_{o}^{2}=L+M(\rho U)^{n}
$$

where $E_{o}$ is the anemometer output voltage, $L$ and $M$ are constants for a given wire temperature and total temperature, and $n$ is chosen to give the best fit in a least-squares sense. ${ }^{20}$ However, Eq. 1 is only applicable to hot-wire data collected at the same total temperature for which the calibration was developed. Therefore, when performing a boundary-layer survey, where the mean total temperature varies across the boundary layer, a temperature correction must be employed. To that end, we utilized a new curve fit of the form:

$$
E_{o}^{2}\left(T_{o} / T_{c}\right)=L+M(\rho U)^{n}
$$




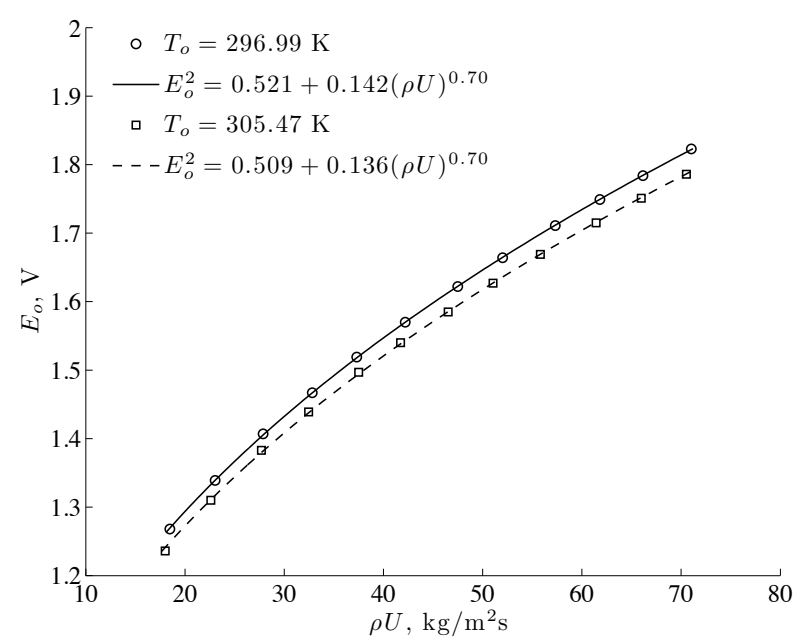

(a) Mass-flux calibrations for different total temperatures.

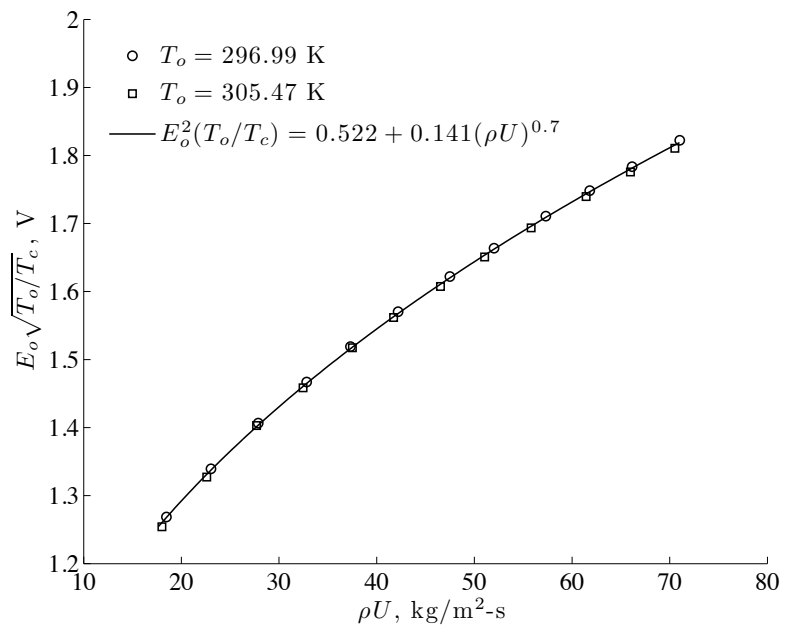

(c) Curve fit to mass-flux calibration data.

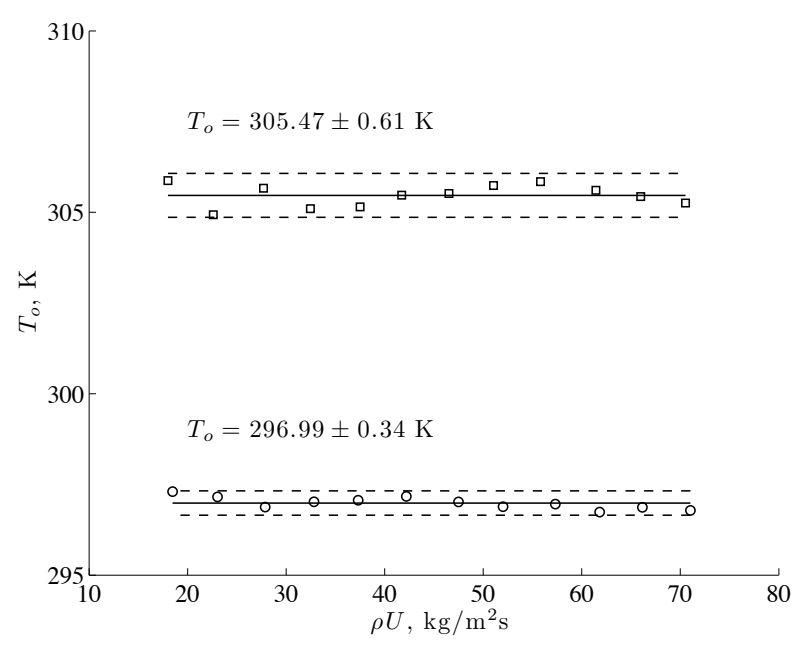

(b) Total-temperature variation during mass-flux calibration.

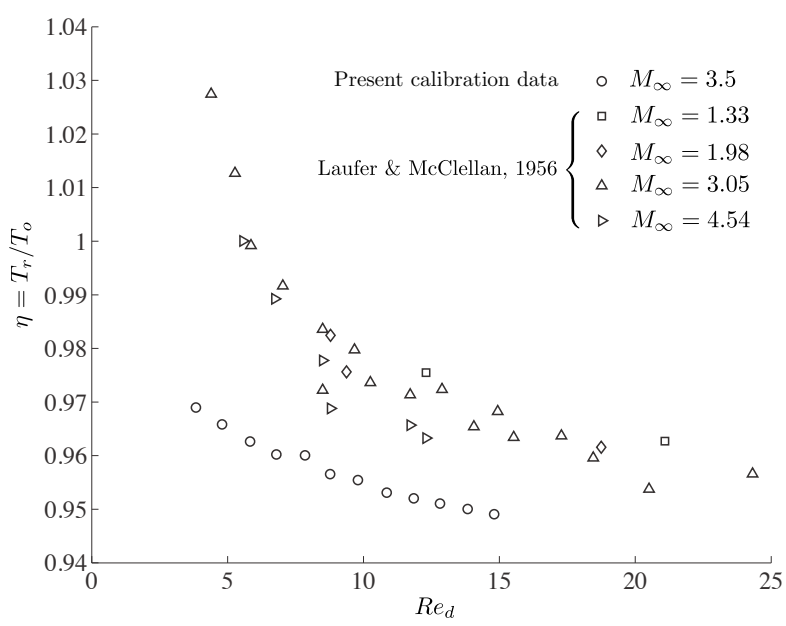

(d) Wire recovery factor variation with wire Reynolds number.

Figure 5. Example calibration and curve fit for a constant-temperature hot-wire anemometer. The freestream Mach number was 3.5 and the nominal overheat ratio at $T_{o}=297 \mathrm{~K}$ was $\tau=0.9$.

where the output voltage is scaled by $\sqrt{T_{o} / T_{c}}$. Here, $T_{o}$ is the mean total temperature at which $E_{o}$ was measured and $T_{c}$ is a nominal calibration temperature. The successful correlation of mass-flux calibration data via Eq. 2 is demonstrated in Fig. 5c, where the calibration data are plotted using the proposed temperature scaling and a $T_{c}$ equal to $297 \mathrm{~K}$. Note that the temperature difference between the two mass-flux calibrations is representative of that encountered during a typical boundary-layer survey.

To convert voltage time series to mass-flux time series via Eq. 2, the mean total temperature is required. That can be obtained by measuring the resistance of an unheated wire in the flow, $R_{r}$. Due to the resistancetemperature characteristic of the platinum-plated tungsten, the measured resistance is related to the wire recovery temperature via:

$$
T_{r}=T_{r e f}+\frac{1}{\alpha}\left(\frac{R_{r}}{R_{r e f}}-1\right)
$$

where $R_{r e f}$ is the wire resistance at the reference temperature $T_{r e f}$, and $\alpha$ is the temperature coefficient of resistance for platinum-plated tungsten $\left(0.0036 \mathrm{~K}^{-1}\right)$. Then, the total temperature is calculated by dividing $T_{r}$ by the wire recovery factor, $\eta=T_{r} / T_{o}$. In a supersonic flow, however, the wire recovery factor is a function of the wire Reynolds number, $R e_{d}=\rho U d / \mu_{o}$ (where $\mu_{o}$ is the dynamic viscosity at $T_{o}$ ), for $R e_{d}<20{ }^{22}$ Since the wire Reynolds number was typically below 20 in the present measurements, this dependency must be characterized. To that end, an unheated-wire Reynolds-number sweep at constant total temperature was 
performed in the PCT to determine the recovery factor for our probe design. A typical set of recovery-factor data is shown in Fig. 5d, and for comparison, the recovery factor data of Laufer and McClellan ${ }^{22}$ for a range of wire Reynolds numbers and Mach numbers is also shown. Qualitatively, the data are similar in that $\eta$ increases with decreasing wire Reynolds number. On the other hand, the quantitative differences are likely due to particular differences in the hot-wire probe designs. Nevertheless, the recovery factor data measured for our probe design gave the most accurate total-temperature profiles.

With the mass-flux and recovery-factor calibrations obtained for a given wire sensor, the acquisition of hot-wire data proceeded as follows. First, an unheated-wire survey of the boundary layer was performed. At each $y$-location in the survey, the wire resistance was measured. Next, a hot-wire survey of the boundary layer was performed, and at each $y$-location, the anemometer output voltage was measured. Specifically, the mean voltage, $\overline{E_{o}}$, was read with a digital volt meter and the fluctuating voltage, $e_{o}^{\prime}(t)$, was amplified, band-pass filtered, and sampled with a 14-bit A/D.

Analysis of the hot-wire data then proceeded as follows. Starting with the first point in the profile, the recovery temperature was calculated from the measured unheatedwire resistance. Since the wire Reynolds number at that point is not known a priori, $\eta$ was initially set to the boundary-layer edge value. Then, an initial estimate for the total temperature was given by: $T_{o}=T_{r} / \eta$. With the mean output voltage, $\overline{E_{o}}$, and the total-temperature estimate, Eq. 2 was used to calculate an estimate for the mean mass-flux. Using the mass-flux and total-temperature estimates, the wire Reynolds number was calculated. With that, and the recovery-factor calibration, a new estimate for the recovery factor was obtained. This procedure was repeated until the mean mass-flux and the mean totaltemperature converged to constant values. Normally, this required only 3 to 4 iterations. Subsequent points in the

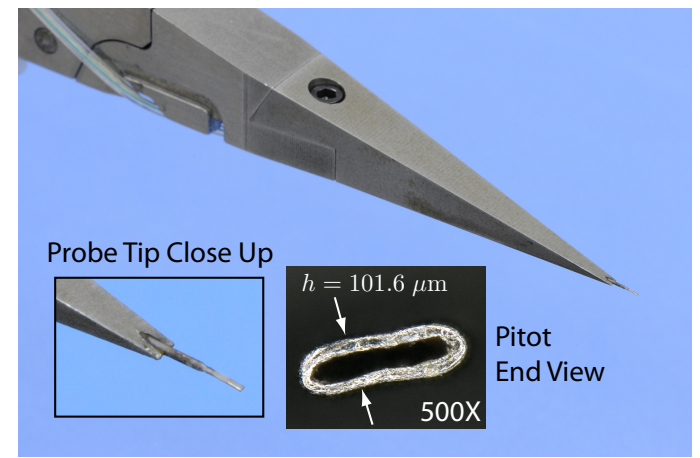

Figure 6. Pitot probe used for boundary-layer measurements. profile were analyzed with the same procedure. Once the mean total-temperature profile was known, the output voltage time series, $E_{o}=\overline{E_{o}}+e_{o}^{\prime}$, for each point in the survey was converted to mass-flux time series via Eq. 2.

In the preceding discussion, the hot-wire output was assumed to be independent of the Mach number. Because this is valid only for Mach numbers greater than $1.2,{ }^{23}$ no hot-wire measurements were made where the local Mach number fell below that value. To identify that location in the boundary layer, pitot surveys were performed to measure Mach-number profiles. An image of the pitot probe used for those measurements is shown in Fig. 6. The pitot probe was designed with the same body as the hot-wire probe to minimize mean-flow distortion, and the end of the pitot probe was flattened to a height of $101.6 \mu \mathrm{m}$. For the thinnest boundary-layer considered in this study, the probe-tip height was $\approx 0.2 \delta$. The pitot pressure was measured with a Kulite pressure transducer (XCQ-062-25A) that was coupled to the pitot probe via $1.27 \mathrm{~m}$ of 0.508 $\mathrm{mm}$ I.D. tubing. The small dead volume of the pressure transducer and the micro-bore tubing minimized the settling time of the pitot probe, which was found to be $\approx 5$ seconds. For boundary-layer surveys with the pitot probe, the wall-normal positions were set with the same procedure that was implemented for the hot-wire probe. The measured pitot pressure at each location in the boundary layer was converted to Mach number using isentropic relations in the subsonic portion of the boundary layer and the Rayleigh pitot formula in the supersonic portion of the boundary layer. In either case, the static pressure was assumed to be constant across the boundary layer.

\section{II.D. Isolated Roughness Elements}

The isolated roughness elements were fabricated with a low compressibility polyester shim stock material that is available in a range of heights $(k=76.2 \mu \mathrm{m}$ to $635 \mu \mathrm{m})$ and is easily cut into arbitrary planforms via laser ablation. For the present experimental program, square and circular planforms were fabricated (see Fig. 7 for example images of roughness elements). The square roughness elements were also rotated $45^{\circ}$ to form a diamond-shaped planform. Placement of the roughness elements on the flat-plate model was aided by a shim-stock mask that has cutouts, in the shape of the roughness element, at the desired spatial locations. With the mask laid down on the model surface, roughness elements were placed in the cutout 

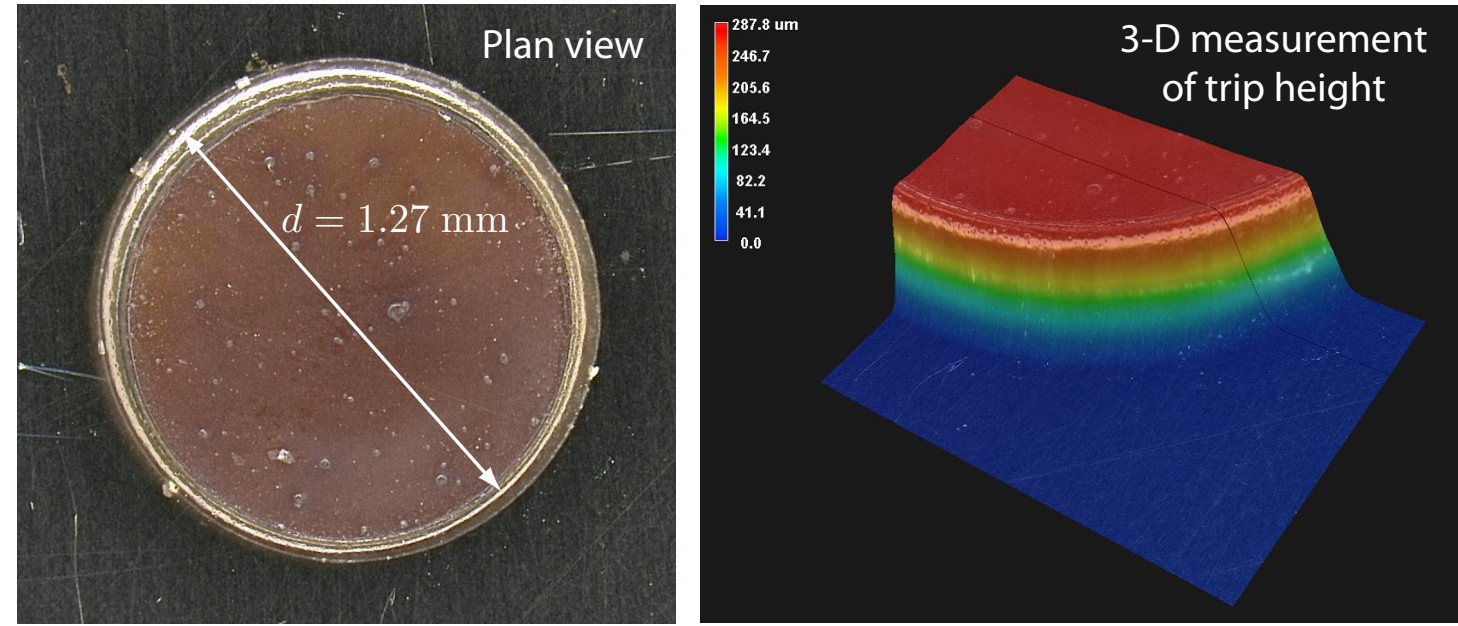

(a) Circular planform, isolated roughness element. $d=1.27 \mathrm{~mm}, k=254 \mu \mathrm{m}$.
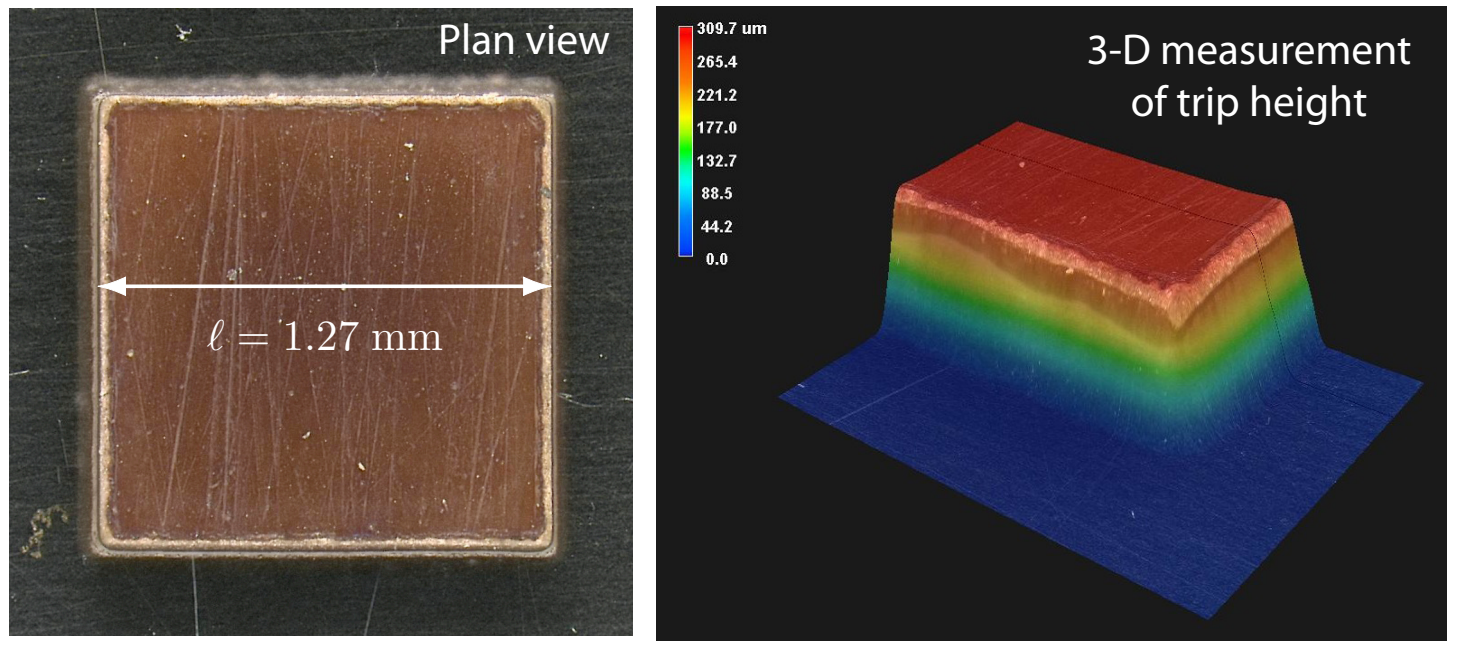

(b) Square planform, isolated roughness element. $\ell=1.27 \mathrm{~mm}, k=254 \mu \mathrm{m}$.

Figure 7. Example images and height measurements of isolated roughness elements.

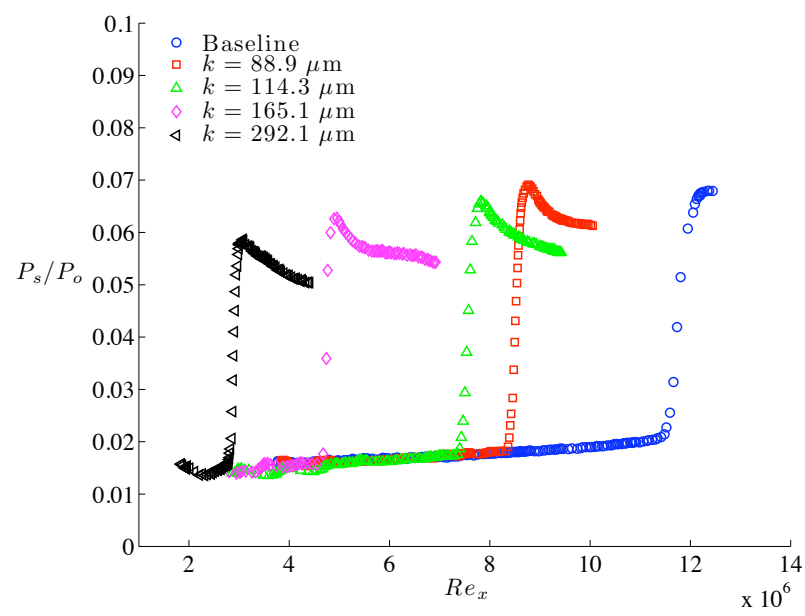

(a) Quiet-flow conditions.

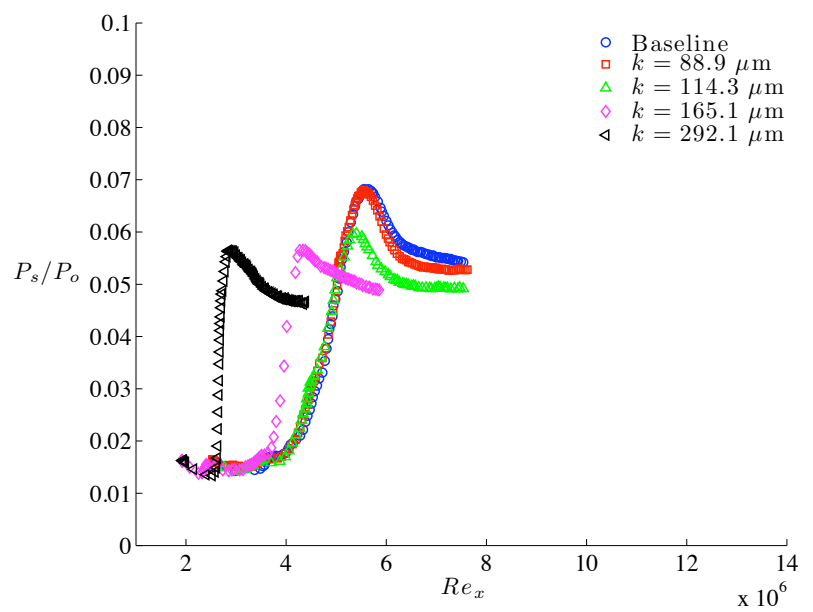

(b) Noisy-flow conditions.

Figure 8. Preston-tube data showing transition onset for isolated roughness elements of different heights. 
Table 1. Transition onset data and roughness parameters for isolated roughness elements on the flat-plate model.

\begin{tabular}{ccccccc}
$k, \mu \mathrm{m}$ & $R e_{x} \times 10^{-6}$ (onset) & $P_{o}, \mathrm{kPa}$ (onset) & $\delta, \mu \mathrm{m}$ & $k / \delta$ & $R e_{k k}$ & Bleed Valves \\
\hline 0.0 & 11.60 & 634.3 & 212.8 & - & - & open \\
88.9 & 8.40 & 462.0 & 249.3 & 0.357 & 146.7 & open \\
114.3 & 7.45 & 406.8 & 265.7 & 0.430 & 223.8 & open \\
165.1 & 4.70 & 258.6 & 333.3 & 0.495 & 265.8 & open \\
292.1 & 2.85 & 155.1 & 430.3 & 0.679 & 624.3 & open \\
\hline 0.0 & 4.40 & 241.3 & 345.0 & - & - & closed \\
88.9 & 4.40 & 241.3 & 345.0 & 0.258 & 49.6 & closed \\
114.3 & 4.40 & 241.3 & 345.0 & 0.331 & 88.4 & closed \\
165.1 & 3.75 & 213.7 & 366.6 & 0.450 & 183.2 & closed \\
292.1 & 2.60 & 144.8 & 445.4 & 0.656 & 523.6 & closed \\
\hline
\end{tabular}

regions and attached to the model with a drop of cyanoacrylate adhesive. After removal of the mask, the roughness height was measured with a Keyence VHX600 digital microscope system that scans the height of the element and digitally reconstructs the three-dimensional shape. Examples of that measurement are shown in Fig. 7.

\section{Results}

\section{III.A. Trip Sizing Study}

In preparation for the forthcoming flat plate boundary-layer measurements, a brief trip-sizing study was performed $^{\mathrm{a}}$ to identify the roughness-element height required to force transition on the flat-plate model. For that study, roughness elements with a diamond-shaped planform and heights ranging from 89 to 292 $\mu \mathrm{m}$, were placed on the model centerline, $15.2 \mathrm{~mm}$ downstream from the leading edge. Transition onset was detected with a Preston tube on the model surface, $356 \mathrm{~mm}$ downstream from the model leading edge. For each trip height, the unit Reynolds number was swept over a range of values, by slowly varying the stagnation pressure at a constant total temperature, and the pressure from the Preston tube was recorded. The Preston-tube pressure for each trip case considered, normalized by the freestream total pressure $\left(P_{s} / P_{o}\right)$, is presented in Fig. 8. The length Reynolds number, $R e_{x}$, in the figures is based on the distance from the model leading edge to the Preston tube and the freestream conditions. In general, $P_{s} / P_{o}$ displays a gradual increase with increasing Reynolds number - a result of the decreasing laminar boundary-layer thickness. Once transition onset moves to the location of the Preston tube, a rapid increase in $P_{s} / P_{o}$ is observed. For quiet-flow conditions (Fig. 8a), where the bleed valves are open, the onset of natural transition on the flat-plate model occurs at $R e_{x} \approx 11.6 \times 10^{6}$. Then, with roughness elements of increasing height, transition onset moves progressively to lower $R e_{x}$. The transition-onset Reynolds numbers for each roughness-element height, and the corresponding roughness parameters $k / \delta$ and $R e_{k k}$, are presented in Table 1 . Here, $\delta$ is the undisturbed boundary-layer thickness at the trip location. The roughness Reynolds number, $R e_{k k}$, is based on undisturbed conditions at the trip location and trip height, $k$. As expected, the transition-onset Reynolds number decreases with an increase in either roughness parameter.

Preston-tube data were also collected for noisy-flow conditions (Fig. 8b and Table 1), where the bleed valves were closed. In that case, the boundary layer in the subsonic approach spills over the nozzle bleed slots and the nozzle contour wall boundary layers become turbulent, thereby producing freestream noise levels that are an order of magnitude higher than those observed under quiet-flow conditions. The effect of the elevated freestream noise levels on transition onset from the isolated roughness elements is dramatic. In particular, the roughness element has no effect on the transition onset value, relative to the baseline case, until the roughness height is above $k=114 \mu \mathrm{m}$. On the other hand, the transition onset Reynolds number appears to be less sensitive to the freestream noise level for the largest roughness height $(k=292.1 \mu \mathrm{m})$. To establish that as fact, however, detailed measurements of the freestream noise levels and boundary-layer

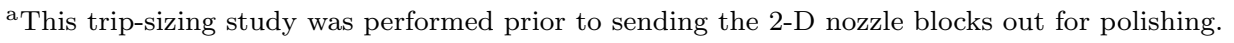




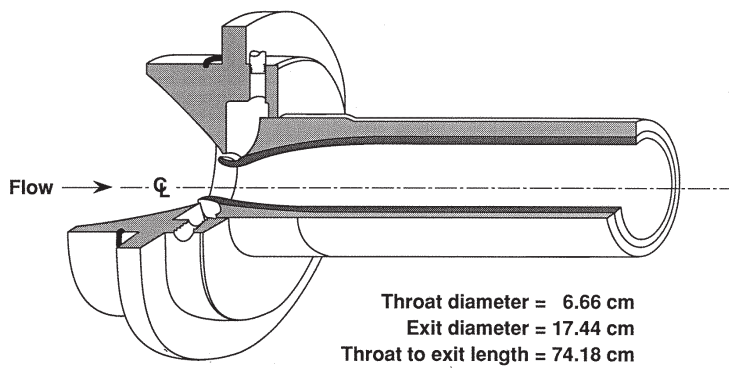

(a) Isometric cutaway view illustrating boundary-layer suction slot and electroformed contour of the Mach 3.5 axisymmetric quiet nozzle.

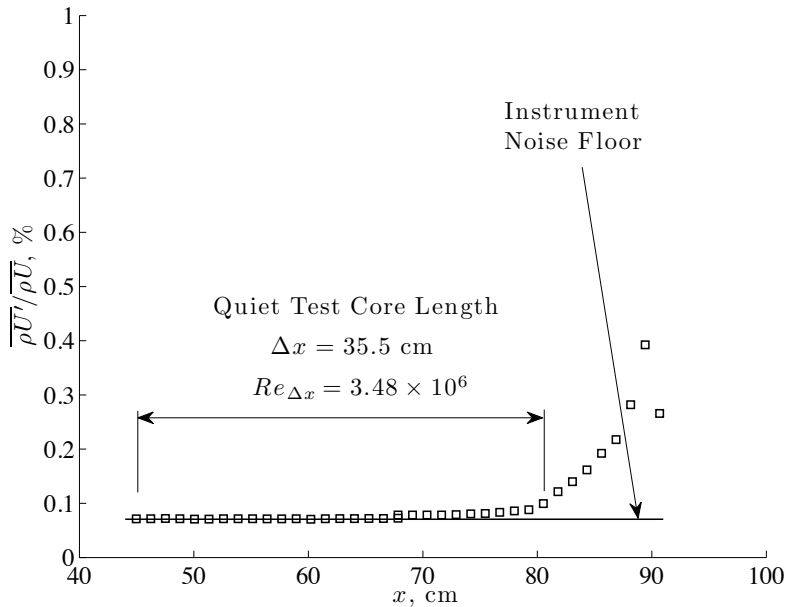

(c) RMS mass-flux along centerline under quiet-flow conditions. Bandwidth was $200 \mathrm{~Hz}$ to $100 \mathrm{kHz}$.

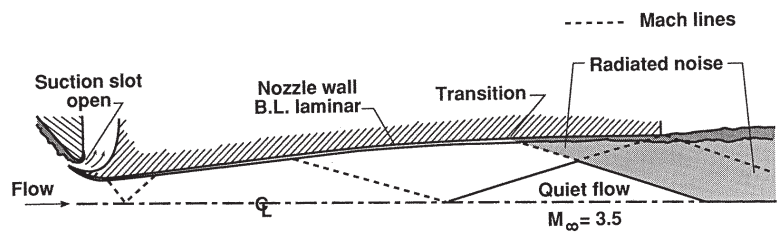

(b) Schematic of quiet test core with bleed valve open for the Mach 3.5 axisymmetric quiet nozzle.

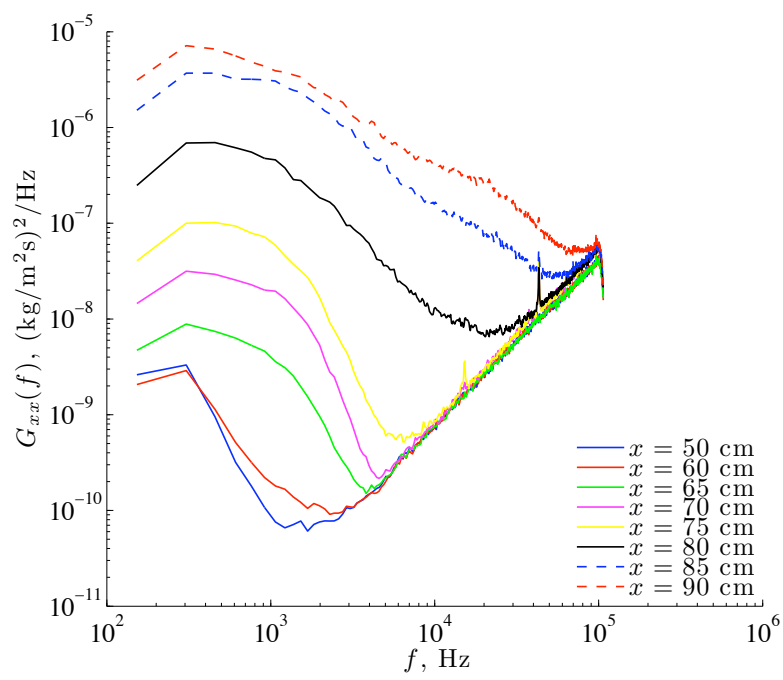

(d) Power spectral density of mass-flux along centerline under quiet-flow conditions.

Figure 9. Measurements of mass-flux fluctuations along the centerline of the SLDT Mach 3.5 axisymmetric nozzle under quiet flow conditions (bleed values open). $P_{o}=172.4 \mathbf{k P a}, T_{o}=311 \mathbf{K}$, and $R e / m=9.81 \times 10^{6}$.

disturbances under quiet-flow and noisy-flow conditions are required. Nevertheless, the Preston-tube data display a general sensitivity to the freestream noise level and underscore the potential need for a quiet-flow facility to perform studies of roughness-induced transition.

The forthcoming flat plate boundary-layer measurements will be performed at a freestream unit Reynolds number of $9.81 \times 10^{6} / \mathrm{m}$ to maximize the extent of quiet flow over the length of the model. Initially, we will consider a roughness element with a diamond-shaped planform, placed $41.3 \mathrm{~mm}$ from the leading edge, and a height of $\approx 381 \mu \mathrm{m}\left(R e_{k k} \approx 550\right)$. This matches the configuration in the computational simulations of Choudhari et al. ${ }^{10}$ Based on the results of the present trip-sizing study, transition is expected to occur on the model at the desired flow condition and roughness height.

\section{III.B. Freestream Measurements}

Prior to the cone model installation in the SLDT, an experiment was performed to characterize the disturbance environment of the Mach 3.5 axisymmetric quiet nozzle. Figure 9a shows an isometric cutaway view that illustrates the boundary-layer suction slot and the electroformed contour of the nozzle. A schematic of the quiet test core with the bleed valve open is shown in Fig. 9b. The freestream disturbances were measured along the nozzle centerline with a hot-wire anemometer. The hot-wire was operated in the constanttemperature mode at a high overheat ratio to measure mass-flux fluctuations. The measurements were started $45 \mathrm{~cm}$ downstream from the nozzle throat, which is the upstream boundary of the Mach 3.5 quiet core, and ended $90 \mathrm{~cm}$ downstream from the throat. The normalized RMS mass-flux fluctuations, $\overline{(\rho U)^{\prime}} / \overline{(\rho U)}$, as a 
function of distance from the nozzle throat, $x$, are presented in Fig. 9c. Mass flux power spectral densities (PSD) for selected $x$-locations are shown in Fig. 9d. All data were acquired at a freestream unit Reynolds number of $R e / m=9.81 \times 10^{6}$.

For most of the centerline survey region, the RMS mass-flux is approximately $0.07 \%$, which corresponds to the anemometer noise floor. By $80.5 \mathrm{~cm}$ from the throat, the RMS mass-flux reaches the $0.1 \%$ threshold that is commonly used to demarcate the end of the quiet-flow region. ${ }^{11}$ With that definition, the quiet test core length for the present flow conditions is $\Delta x=35.5 \mathrm{~cm}$ and the Reynolds number based on that length is $R e_{\Delta x}=3.48 \times 10^{6}$. Beyond $80.5 \mathrm{~cm}$, the RMS mass-flux increases rapidly due to radiated noise from the transitional nozzle wall boundary layer.

At $x$-locations within the quiet test core $(x<80.5 \mathrm{~cm})$, the mass-flux PSD are dominated by energy that increases with the frequency squared. That $f^{2}$-noise is associated with the constant-temperature anemometer $^{19}$ and accounts for most of the energy in the RMS values presented in Fig. 9c. There is, however, low-frequency energy, in the $100 \mathrm{~Hz}$ to several kilohertz range, that lies above the anemometer noise floor and grows in the downstream direction. The exact source of that energy is unknown at this time and requires further investigation. Nevertheless, the energy contained in that frequency band is so small that it accounts for very little of the total signal energy observed in the quiet test core and furthermore, the low frequencies should not be dynamically relevant to the transition phenomena we are currently investigating. Outside the quiet test core $(x \geq 80.5 \mathrm{~cm})$, the mass-flux PSD display a significant increase in energy across a broad frequency range - an increase that is due to radiated noise from the transitional nozzle wall boundary layer.

\section{III.C. Boundary-Layer Measurements on the $7^{\circ}$ Half-Angle Cone Model}

Following the freestream disturbance measurements in the Mach 3.5 axisymmetric quiet nozzle, the $7^{\circ}$ half-angle cone model was installed in the SLDT. A picture of the cone-model installation, positioned at zero angle of attack, is shown in Fig. 10. The tip of the cone model was placed $2.54 \mathrm{~cm}$ downstream from the upstream boundary of the quiet test core. The axial travel of the cone-model traverse ranged from $69.1 \mathrm{~mm}$ to $297.7 \mathrm{~mm}$ from the cone tip. Based on the length of the quiet test core at the nominal test condition of $R e / m=9.81 \times 10^{6}$, the entire measurement region of the cone model, including the tip region, was within the quiet test core.

Boundary layer measurements were first made on the baseline cone model (without a roughness element) to evaluate the measurement techniques. To that end, pitot surveys were performed at several

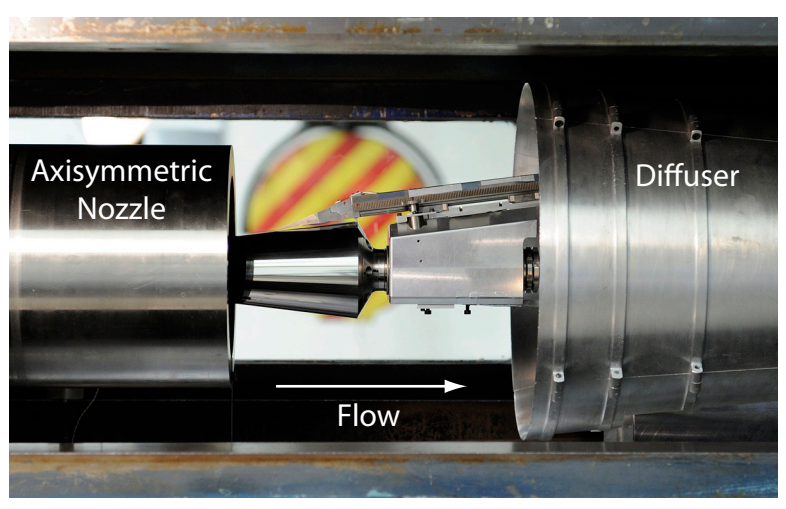

Figure 10. Installation of the $7^{\circ}$ half-angle cone model in the SLDT. different axial locations with a fixed azimuthal angle. Two azimuthal angles were considered in the measurements: $\phi=-45^{\circ}$ and $\phi=135^{\circ}$ (an angle of $\phi=0^{\circ}$ is defined along the top ray of the cone). At the same locations, hot-wire and unheated-wire surveys of the boundary layer were performed with a calibrated hot-wire sensor to measure the mass flux and total temperature, respectively. The measurements were then compared to a laminar mean-flow computation of the flow over the cone-model geometry at zero angle of attack. The computation was performed with matching freestream conditions and the measured wall-temperature distribution, which, starting from an adiabatic temperature near the front of the cone, increased along the cone length. The mean-flow was obtained by solving the two-dimensional Navier-Stokes equations in axisymmetric coordinates using the 5th-order accurate weighted essentially nonoscillatory (WENO) scheme for space discretization. ${ }^{24}$

The measured Mach number profiles for six axial locations and the two azimuthal angles considered are presented in Fig. 11. The computed Mach number profiles are also shown in the figure. As expected, for the low Reynolds number at which the measurements were made, the Mach number profiles are indicative of a laminar boundary layer. The agreement between the measured and computed profiles is generally very good. Throughout most of the boundary layer the difference is less than 5\%; although near the wall, the difference exceeds $10 \%$ in some cases. Remarkably, the agreement between the measured and computed profile at the 


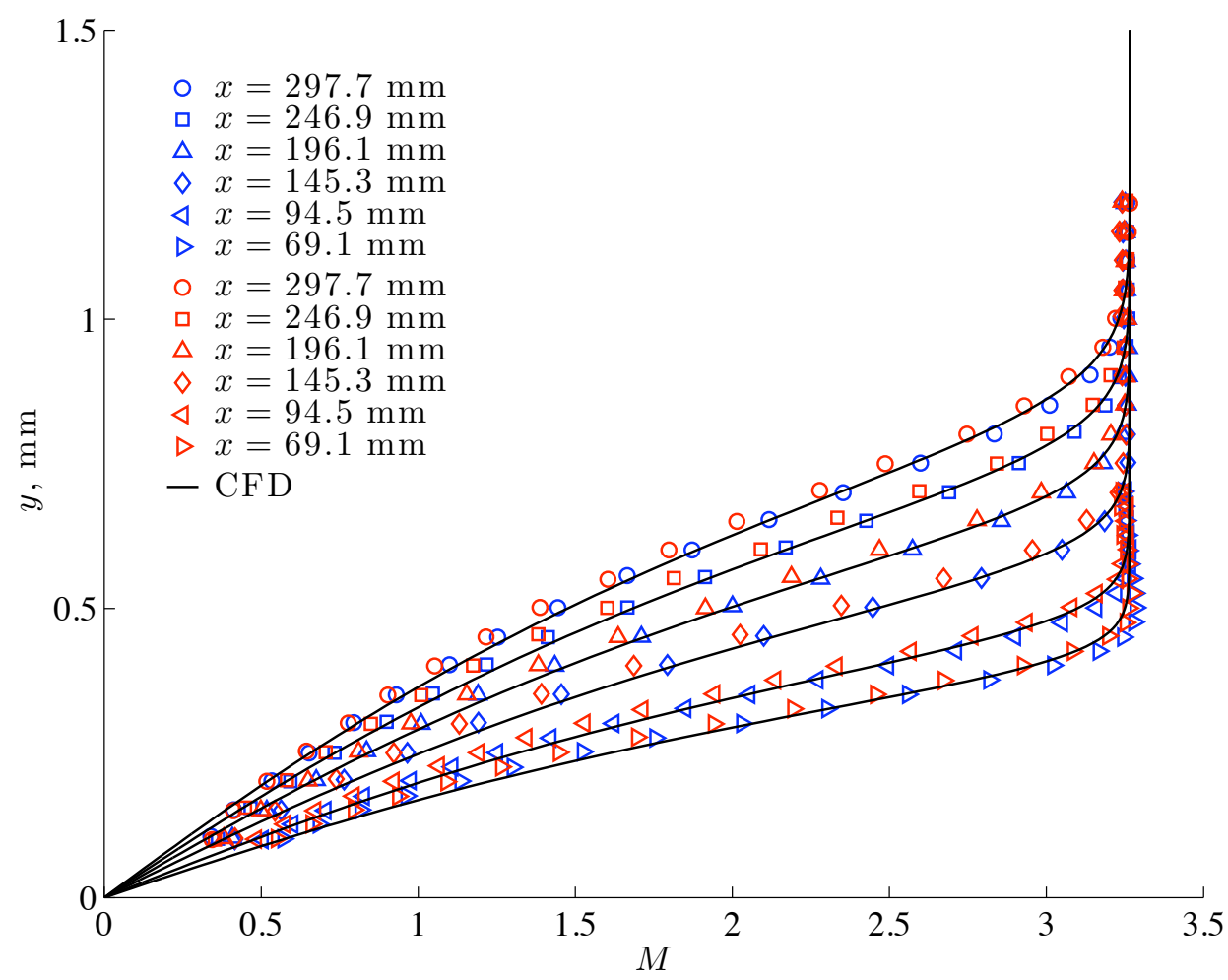

Figure 11. Measured and computed Mach number profiles on the $7^{\circ}$ half-angle cone model at zero angle of attack. Blue symbols denote data acquired at an azimuthal angle of $\phi=-45^{\circ}$ and red symbols denote data acquired at an azimuthal angle of $\phi=135^{\circ}$.

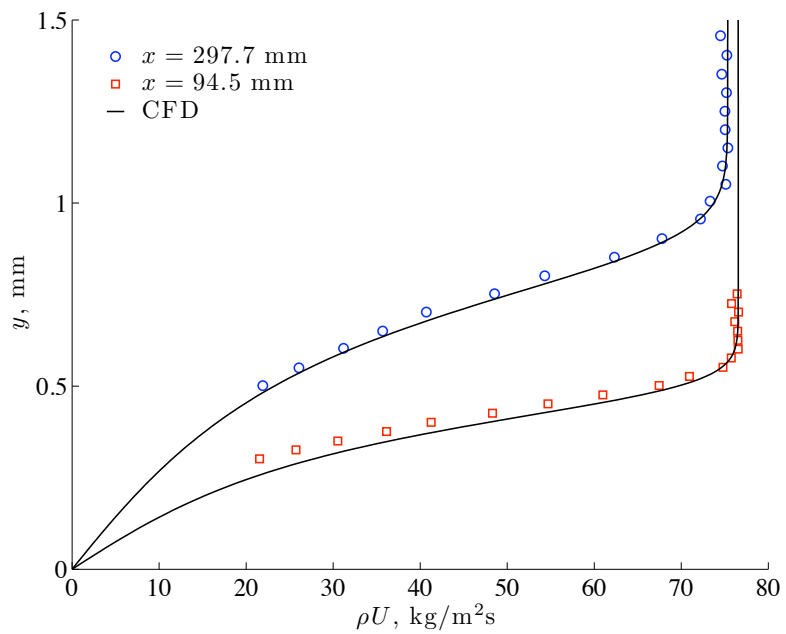

(a) Mass-flux profiles.

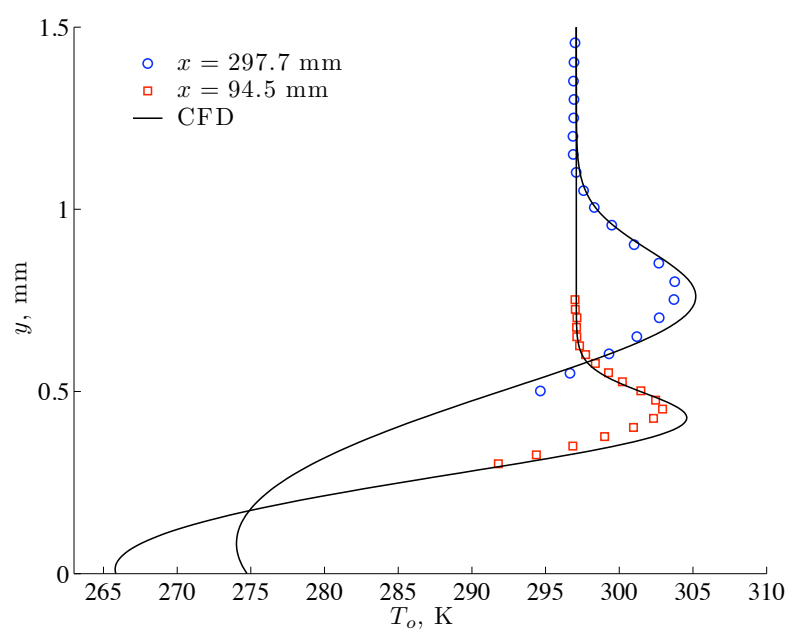

(b) Total-temperature profiles.

Figure 12. Measured and computed mass-flux and total-temperature profiles on the $7^{\circ}$ half-angle cone model at zero angle of attack and an azimuthal angle of $\phi=-45^{\circ}$. 
most forward station $(x=69.1 \mathrm{~mm}$ ) is good, considering the boundary-layer thickness is less than $0.5 \mathrm{~mm}$ and the pitot height is a significant fraction of the boundary-layer thickness $(\approx 0.2 \delta)$. The random uncertainty associated with the Mach-number measurement, which accounts for random uncertainties in the pitot pressure, freestream total pressure, and wall static pressure, is less than $2 \%$ through most of the boundary layer, except in the subsonic region of the boundary layer where it can exceed $10 \%$. The remaining difference between the measured and computed Mach-number profile is due, in part, to systematic uncertainties in the measurement. Probe interference is one source of systematic uncertainty and the Mach number measurement very near the wall is likely biased by that. For the most forward measurement station, the slight overshoot in the Mach number, relative to the computed profile, is also evidence of probe interference. That effect was previously observed by Kendall, ${ }^{25}$ who found that the overshoot was eliminated once the pitot-probe height was less than or equal to $12 \%$ of the boundary-layer thickness. At the lower Mach number of the current investigation $\left(M_{\infty}=3.5\right.$ versus $M_{\infty}=5.8$ in Kendall's study), however, the probe-height requirement may be less restrictive as no discernible overshoot in the Mach number was observed at locations where the pitotprobe height was as large as $0.15 \delta$. A second source of systematic uncertainty is due to a slight misalignment of the cone model relative to the freestream direction. The misalignment is implied by the Mach-number difference, at any given height in the boundary layer, between the two azimuthal angles. That difference was found to be repeatable and could not be accounted for by random error alone. Auxiliary measurements, such as wall static pressures at different azimuthal angles, support the conclusion that the cone is slightly misaligned (on the order of $0.1^{\circ}$ ).

The measured mean mass-flux and total-temperature profiles for two axial stations and a single azimuthal angle $\left(\phi=-45^{\circ}\right)$ are shown in Fig. 12. The computed profiles are also shown for comparison. Note that the lowest points in the profiles correspond to the locations where the Mach number was measured to be $\approx 1.2$. Generally, the agreement between the measured and computed profiles is good. For the rearward station at $x=297.7 \mathrm{~mm}$, the difference between the measured and computed mass-flux profile is $<5 \%$, while that for the total-temperature profile is $<2 \%$. At the most forward station, however, the difference in the mass-flux profile exceeds $10 \%$ for points closest to the wall. The difference in total-temperature in that case is still less than 2\%. As with the Mach-number profiles, the relative difference between the measured and computed mass-flux profiles is likely due to systematic errors caused by cone misalignment and probe interference. The relative magnitude of these systematic errors is presently unknown, but future work will improve on the cone alignment to remove that bias, leaving only the effect due to probe interference. Profiles of mass-flux fluctuations are not shown here because, even though the surveys were performed downstream of the neutral stability point, no instabilities were detected. This is not too surprising because the computed neutral stability point for the present test conditions is about $50 \mathrm{~mm}$ from the cone tip and N-factors are less than 4 over the survey region. In that case, the mass-flux fluctuations associated with the instabilities are very likely below the noise floor of the anemometer.

Overall, the preceding data demonstrate that quantitative measurements, with accuracy in the $5 \%$ range, can be made in the thin $(\delta \sim 1 \mathrm{~mm})$ supersonic laminar boundary layers on our small-scale models. To achieve that, however, particular attention was paid to the probe-body design, the wall-normal positioning of the probes in the boundary layer, and the calibration of the hot-wire sensor at the low wire Reynolds numbers to which it was exposed.

\section{III.C.1. Boundary-Layer Measurements Downstream of an Isolated Roughness Element}

Continuing along the path of measurement-technique development, a single roughness element was placed on the cone model and boundary-layer surveys of the roughness wake were performed. With these measurements, the critical issues related to testing with an isolated roughness element were identified. The diamond shaped roughness element, which was located $68.6 \mathrm{~mm}$ from the cone tip, was $254 \mu \mathrm{m}$ in height, and had an edge length of $1.33 \mathrm{~mm}$. A photograph of the roughness element on the cone model is shown in Fig. 13a and a height scan of the roughness element, performed with the Keyence digital microscope, is shown in Fig. 13b. For the nominal unit Reynolds number at which the boundary-layer surveys were performed $\left(\operatorname{Re} / m=9.81 \times 10^{6}\right)$, the roughness Reynolds number was $R e_{k k}=527$ and $k / \delta$ was 0.5 . The boundary-layer measurements in the present work were limited to the centerline ray emanating from the roughness element, as remote-controlled positioning of the azimuthal angle was not available when the measurements were performed.

Mach number profiles at several centerline stations downstream from the roughness element are presented in Fig. 14. Here, the wall-normal and streamwise positions were normalized by the trip height, $k$. At the first four measurement stations shown in the figure, a significant region of subsonic flow, extending far from 


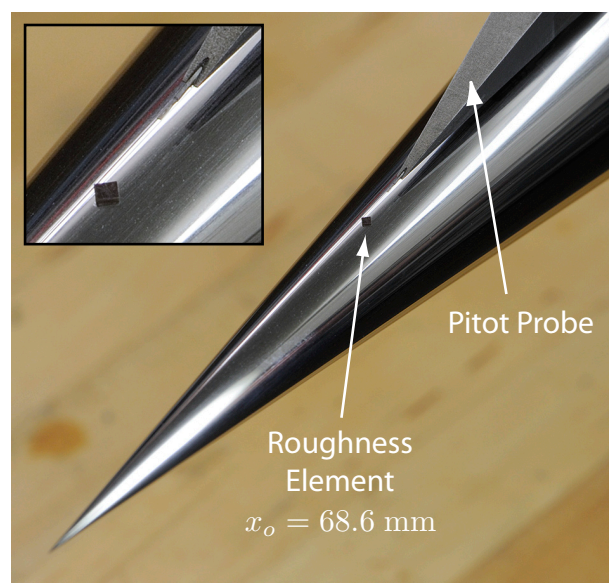

(a) Placement of roughness element on cone model.

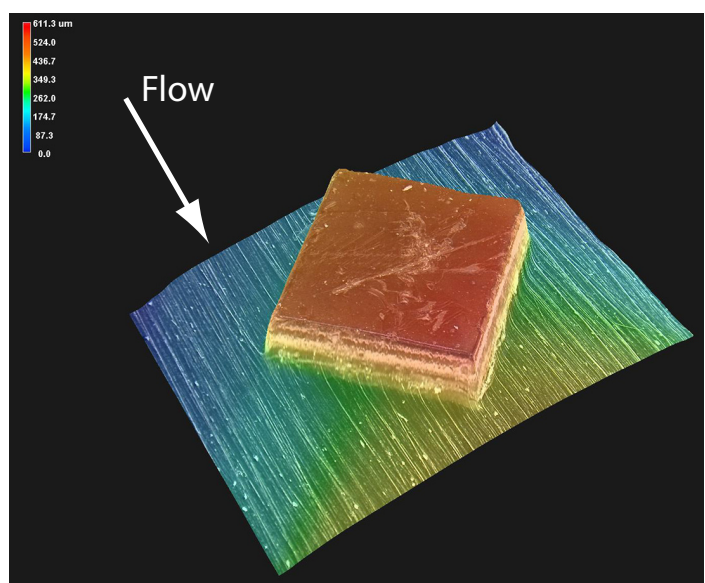

(b) Height scan of the diamond planform roughness element.

Figure 13. Diamond planform roughness element on the $7^{\circ}$ half-angle cone model. The trip edge length was 1.33 mm and the nominal height was $k=254 \mu \mathrm{m}$.

the wall, is observed. That is followed by a region of high wall-normal shear that extends to the edge of the boundary layer. This shear-layer region is also observed to spread in the wall-normal direction with increasing downstream position. By $\left(x-x_{o}\right) / k=200$, however, the Mach number profile is observed to increase monotonically away from the wall, and with subsequent downstream positions, the profiles become fuller and reminiscent of a turbulent boundary layer. Note that the edge of the boundary layer was not reached for these downstream positions due to limited travel in the wall-normal axis of the cone traverse. Mean mass-flux profiles for the same centerline stations are shown in Fig. 15. In the figure, each profile is normalized by the mean mass-flux at the edge of the boundary layer and no data is shown in regions of the flow where the local Mach number fell below 1.2. The mass-flux profiles are similar to the Mach-number profiles in that the development of the wake flow is characterized by a spreading shear-layer region lying away from the wall, followed by development into a fuller profile at the most downstream locations.

The profile measurements up to $\left(x-x_{o}\right) / k=177$ are consistent with a wake flow that is dominated by a low-speed streak on the centerline. That view is supported by the simulations of Choudhari et al. ${ }^{10}$ where the mean flow over a similar diamond shaped roughness element, immersed in a Mach 3.5 flat plate boundary layer, was computed. There, the horseshoe vortex system that begins near the front of the roughness element produces an upwelling of fluid along the centerline of the roughness-element wake. That results in a low-speed streak extending behind the element, a substantially increased boundary-layer thickness, and a shear-layer region lying away from the wall.

Profiles of the fluctuating mass-flux, $\overline{(\rho U)^{\prime}}$, at several centerline stations in the roughness wake are shown in Fig. 16. Here, the RMS values were calculated over a frequency bandwidth of 50 to $250 \mathrm{kHz}$ and were normalized by the mean mass-flux at the edge of the boundary layer. Note the scale change, by a factor of ten, between Figs. 16b and 16c. At the first station, $\left(x-x_{o}\right) / k=50$, no mass-flux fluctuations above the anemometer noise floor were detected. At the next station shown in the figure, $\left(x-x_{o}\right) / k=100$, a distribution of mass-flux fluctuations is observed at a height corresponding to the shear-layer region of the mean mass-flux profile. The peak fluctuation level in that distribution is near the point of maximum mean mass-flux gradient. Over the next two stations shown in the figure, the mass-flux fluctuations display substantial growth, with a peak fluctuation of $9 \%$ at $\left(x-x_{o}\right) / k=177$. Again, the peak of the distribution lies near the maximum mean mass-flux gradient and is also observed to move outward as the boundary layer grows in the downstream direction. For subsequent downstream stations, the peak fluctuation level decays somewhat, and the distribution of mass-flux fluctuations broadens significantly across the thickness of the boundary layer. It is in this region of the roughness wake that the mean profiles begin to take on a shape that is characteristic of a turbulent boundary layer.

Mass-flux power spectral densities (PSD) at several centerline stations in the roughness wake are shown in Fig. 17. Here, the mass-flux PSD correspond to the height in the boundary layer where $\overline{(\rho U)^{\prime}}$ was a 


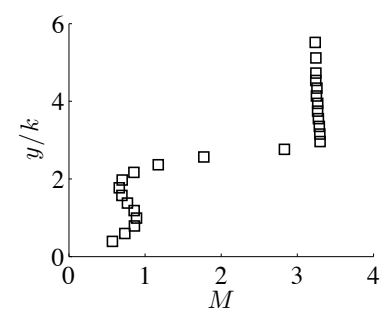

(a) $\left(x-x_{o}\right) / k=50.0$.

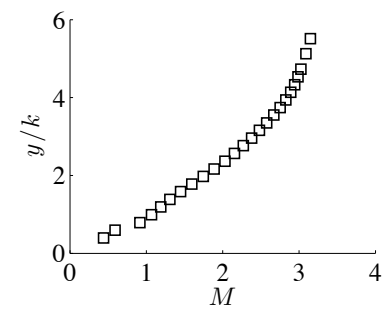

(e) $\left(x-x_{o}\right) / k=200.0$.

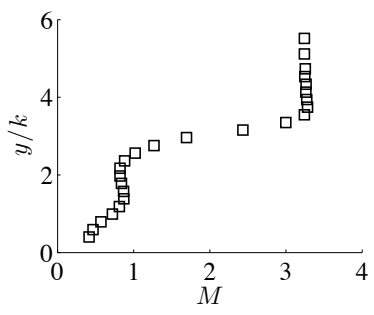

(b) $\left(x-x_{o}\right) / k=100.0$.

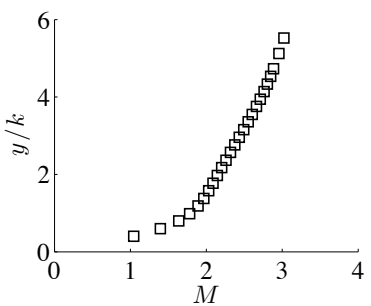

(f) $\left(x-x_{o}\right) / k=250.0$.

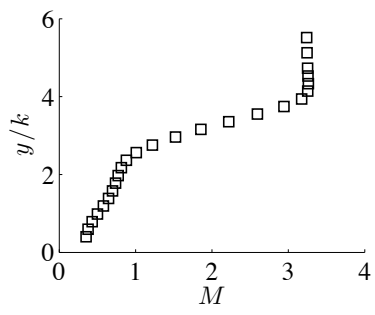

(c) $\left(x-x_{o}\right) / k=150.0$.

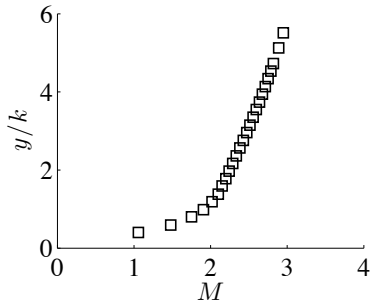

(g) $\left(x-x_{o}\right) / k=300.0$.

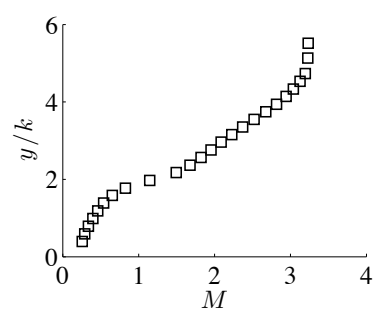

(d) $\left(x-x_{o}\right) / k=177.0$.

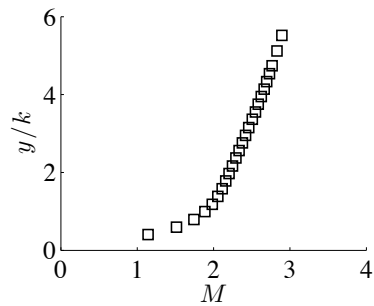

(h) $\left(x-x_{o}\right) / k=400.0$.

Figure 14. Mach number profiles at different downstream locations, $\left(x-x_{o}\right) / k$, along the centerline ray emanating from the diamond planform roughness element. Here, $x_{0}=68.6 \mathrm{~mm}$ denotes the location of the roughness element and the nominal height was $k=254 \mu \mathbf{m}$.

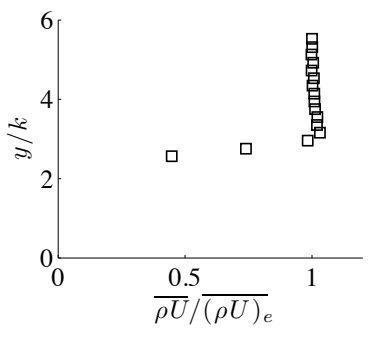

(a) $\left(x-x_{o}\right) / k=50.0$.

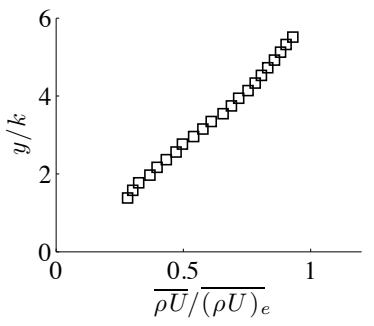

(e) $\left(x-x_{0}\right) / k=200.0$.

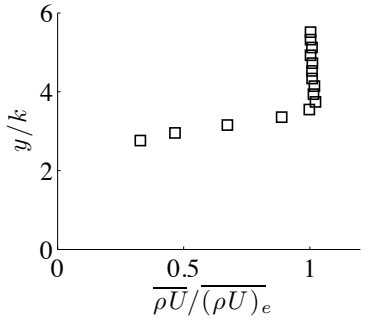

(b) $\left(x-x_{o}\right) / k=100.0$.

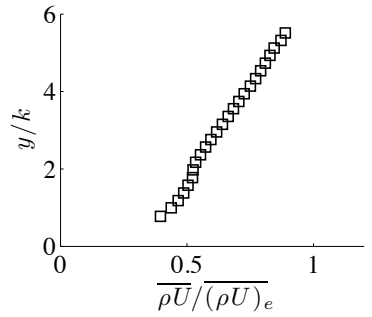

(f) $\left(x-x_{o}\right) / k=250.0$.

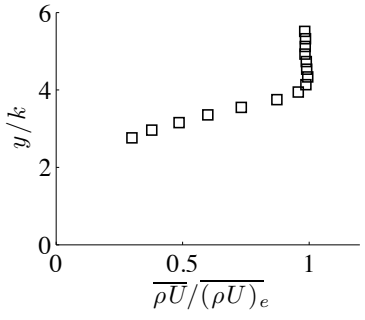

(c) $\left(x-x_{o}\right) / k=150.0$.

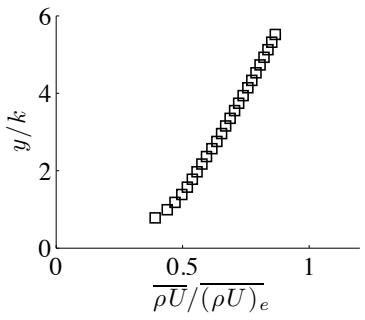

(g) $\left(x-x_{o}\right) / k=300.0$.

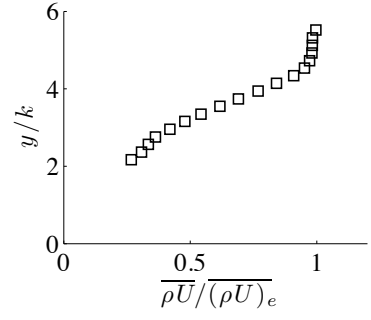

(d) $\left(x-x_{o}\right) / k=177.0$.

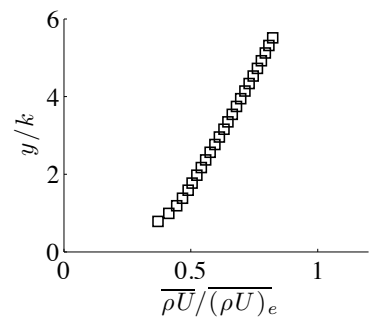

(h) $\left(x-x_{o}\right) / k=400.0$.

Figure 15. Mean mass-flux profiles at different downstream locations, $\left(x-x_{o}\right) / k$, along the centerline ray emanating from the diamond planform roughness element. Here, $x_{o}=68.6 \mathrm{~mm}$ denotes the location of the roughness element and the nominal height was $k=254 \mu \mathrm{m}$. 


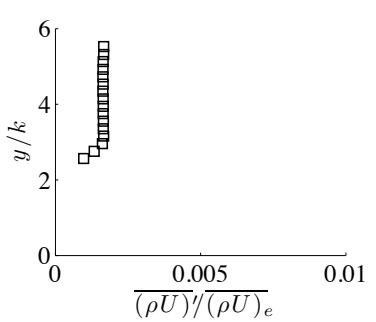

(a) $\left(x-x_{o}\right) / k=50.0$.

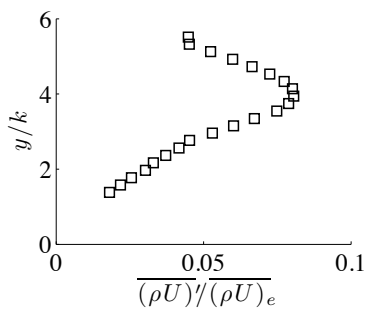

(e) $\left(x-x_{o}\right) / k=200.0$.

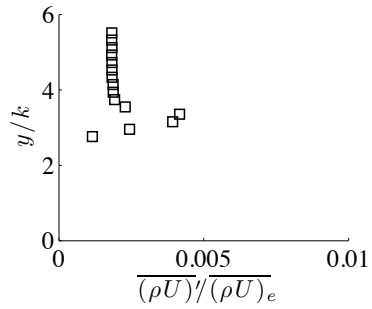

(b) $\left(x-x_{o}\right) / k=100.0$.

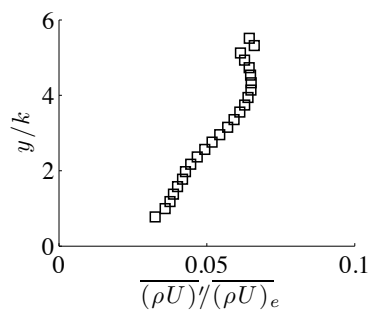

(f) $\left(x-x_{o}\right) / k=250.0$.

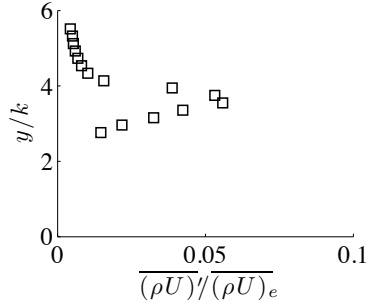

(c) $\left(x-x_{o}\right) / k=150.0$.

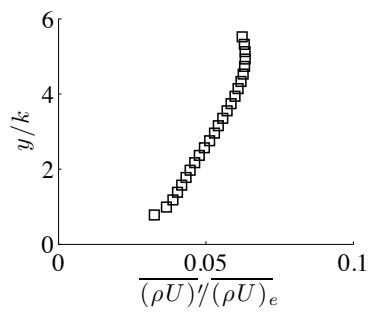

(g) $\left(x-x_{o}\right) / k=300.0$.

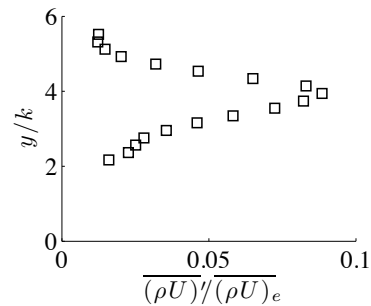

(d) $\left(x-x_{o}\right) / k=177.0$.

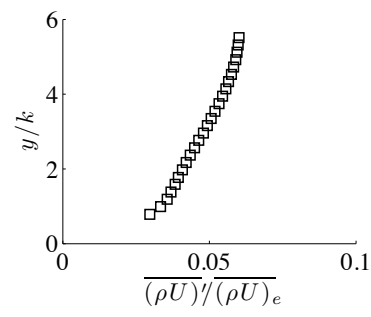

(h) $\left(x-x_{o}\right) / k=400.0$.

Figure 16. Fluctuating mass-flux profiles at different downstream locations, $\left(x-x_{o}\right) / k$, along the centerline ray emanating from the diamond planform roughness element. Here, $x_{o}=68.6 \mathrm{~mm}$ denotes the location of the roughness element and the nominal height was $k=254 \mu \mathrm{m}$. The bandwidth for the measurements was 50 to $250 \mathrm{kHz}$.

maximum. In Fig. 17a, the mass-flux PSD are shown for the full bandwidth of the signal, from $0 \mathrm{~Hz}$ up to the Nyquist frequency of $312.5 \mathrm{kHz}$. At frequencies below $50 \mathrm{kHz}$, some of the spectral energy was found to be contaminated by vibrations of the traverse mechanism and work is currently underway to reduce the vibration issues. Also, the hot-wire signals were low-pass filtered at $200 \mathrm{kHz}$ (upper limit of anti-aliasing filters used) prior to sampling, which accounts for the attenuation in the PSD beyond that frequency. Unfortunately, the spectra indicate that significant energy lies beyond $200 \mathrm{kHz}$ and therefore future measurements will require higher sampling rates and filter cutoff frequencies. For the present measurements, however, some of the attenuated energy can be recovered by dividing the PSD by the squared amplitude of the filter transfer function. Due to noise in the measurement system, that correction is not applicable beyond $250 \mathrm{kHz}$. The PSD shown in Fig. 17b are band limited between 50 and $250 \mathrm{kHz}$ and were corrected for the filter transfer function. Corrected and band-limited spectra like these were used to calculate the RMS mass-flux profiles shown in Fig. 16.

The mass-flux PSD display a broad range of frequencies that experience substantial growth downstream of the roughness element. Generally, the highest energy levels are between 150 and $250 \mathrm{kHz}$ and there, several relatively narrow-band frequencies are observed. The spectral components in that frequency band saturate by $\left(x-x_{o}\right) / k=177$ and then decay with subsequent downstream position. By the last station in the plot, $\left(x-x_{o}\right) / k=250$, the spectrum is nearly devoid of the high-frequency peaks and the spectral energy has shifted to the lower end of the frequency bandwidth. With that shift to lower frequencies, the mean profiles for the Mach number and mass-flux display a change in character towards fuller profiles. The broadband character of that PSD, and the PSD for subsequent downstream stations, is indicative of that for a turbulent flow. However, further measurements and analysis are required to establish whether the boundary layer has reached a fully developed state.

In Fig. 18, the peak RMS mass-flux, normalized by the mean mass-flux at the boundary-layer edge, is plotted as a function of distance downstream from the roughness element. Data are shown for the 50-250 $\mathrm{kHz}$ frequency band, as well as for the three largest peaks in the mass-flux spectra at $f=162 \mathrm{kHz}, 185 \mathrm{kHz}$, and $208 \mathrm{kHz}$. For each peak, the RMS value was calculated over a $\pm 5 \mathrm{kHz}$ frequency band. In general, each case presented in the figure displays a similar character: exponential growth, followed by saturation, and then an asymptotic decay as the flow develops towards a fully developed turbulent flow. Although the data is coarsely spaced in the growth region, the relative growth rate between the three single-frequency cases appears to be very similar.

Recently, Choudhari et al. ${ }^{10}$ performed a spatial stability analysis of the computed streaks that form downstream of a diamond-shaped roughness element immersed in a Mach 3.5 flat plate boundary layer. 


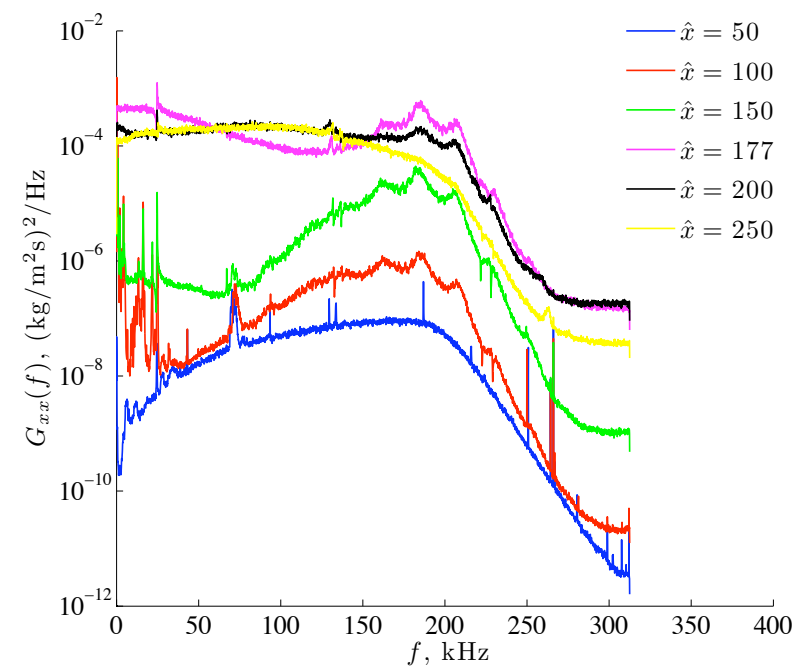

(a) Measured mass-flux power-spectral densities.

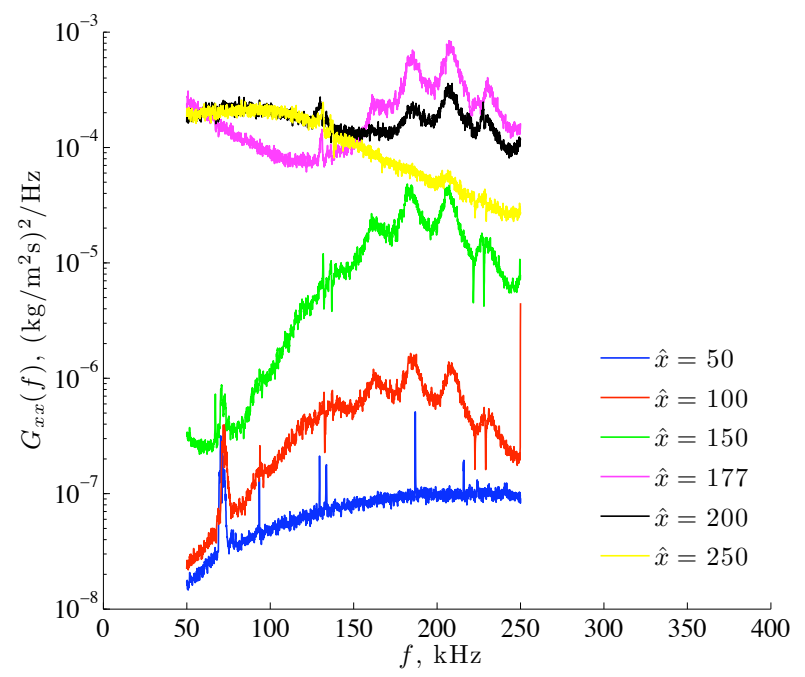

(b) Corrected (for filter cutoff at $200 \mathrm{kHz}$ ) and band limited (50 to $250 \mathrm{kHz}$ ) mass-flux power-spectral densities.

Figure 17. Mass-flux power-spectral densities at different downstream locations, $\hat{x}=\left(x-x_{o}\right) / k$, from the diamond planform roughness element. The spectra shown in the plots correspond to a height in the boundary layer where $\overline{(\rho U)^{\prime}}$ was a maximum.

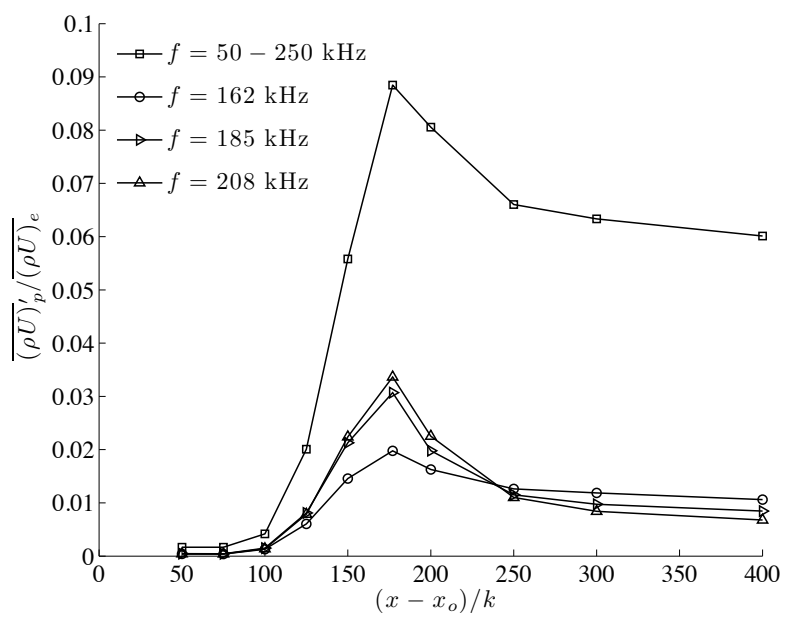

(a) Linear Scale.

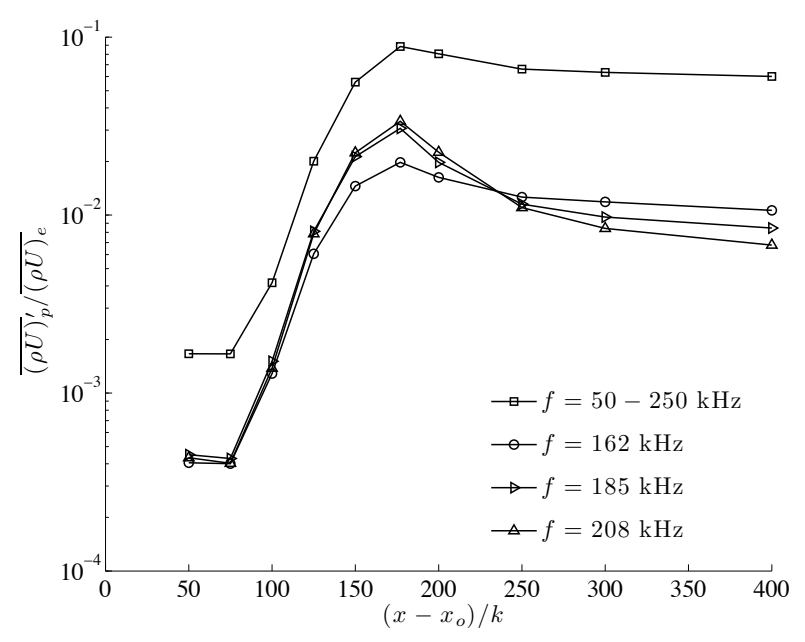

(b) Logarithmic Scale.

Figure 18. Growth of the peak RMS mass flux with downstream distance from the diamond planform roughness element. 
There, the stability at multiple streamwise locations was analyzed by solving a 2-D eigenvalue problem, which was required due to the strongly inhomogeneous character of the roughness wake in both the $y$ and $z$ directions. That stability analysis revealed both even (symmetric or varicose) and odd (antisymmetric or sinuous) modes of instability in the roughness wake. The even mode of instability is particularly relevant to the present work because fluctuations associated with it were found to be concentrated on the centerline of the roughness wake. Furthermore, the even-mode instabilities were found to be concentrated in a region of increased wall-normal shear $(\partial u / \partial y)$ which, due to flow upwelling in the roughness wake, lies several trip heights away from the wall. As for frequencies of the even-mode instabilities, the analysis indicated maximum growth rates in the 100 to $200 \mathrm{kHz}$ range, depending on the specific trip height. Although a quantitative comparison between the simulations of Choudhari et al. and the present measurements cannot be made, both cases share many characteristics that should allow for some qualitative comparisons. For example, both cases consider a zero-pressure-gradient boundary layer with the same unit Reynolds number and similar edge Mach numbers - and the roughness geometry is similar, with $\operatorname{Re}_{k k} \sim 500$ and $k / \delta \sim 0.5$. Given the similar scales between the two cases, it is also reasonable to expect instability frequencies with the same order of magnitude. Overall, the present measurements clearly indicate an instability in the roughness wake that has characteristics generally consistent with the even-mode instability from the analysis. More specifically, fluctuations are concentrated around the high wall-normal-shear region of the roughness-wake profile and the frequencies, which experience the most growth, lie in the 150 to $250 \mathrm{kHz}$ range. To fully confirm the role of streak instabilities during roughness-induced transition, however, additional measurements are required to map out the 2-D modal structure of the instabilities.

\section{Summary and Future Work}

An experimental and computational study, with the specific goal of identifying and quantifying the instability mechanisms leading to transition from an isolated roughness element immersed in a high-speed compressible boundary layer, is currently underway. The ultimate goal is to develop a physics-based methodology for transition prediction that is based on those instability mechanisms. Previously, Choudhari et al. reported on the computational aspects of the research effort. Here, we presented our progress towards quantitative measurements of roughness-induced instabilities in a supersonic boundary layer. A key component of this experimental effort is the NASA Langley Mach 3.5 Supersonic Low-Disturbance Tunnel, in which the freestream noise levels are $<0.1 \%$ and indicative of the low-disturbance environment encountered during high-altitude flight.

A flat-plate trip-sizing study, which was used to identify the roughness height required to force transition on the model, was presented. Included in this study were transition-onset measurements under both quiet and noisy freestream flow conditions. Transition onset from the isolated roughness elements was found to be sensitive to the freestream disturbance level - a result that is in agreement with previous quiet-tunnel measurements.

Surveys of the laminar boundary layer on a $7^{\circ}$ half-angle sharp-tipped cone model were performed with hot-wire anemometry and pitot-pressure measurements. These measurements were particularly challenging due to the small scale of the model and the resulting thin boundary layers $(\delta \sim 1 \mathrm{~mm})$. To achieve accurate quantitative measurements in these boundary layers, considerable effort was focused on the probe-body design, the wall-normal positioning of the probes in the boundary layer, and the calibration of the hotwire sensor at the low wire Reynolds numbers to which it was exposed. Comparison of the measurements to mean-flow computations was used to evaluate the measurement techniques. Generally, the mean Mach number, mass-flux, and total-temperature profiles were in very good agreement with the mean-flow computations. Throughout most of the measured boundary layer, the agreement between the measurements and computations was within $5 \%$, although in some cases, particularly near the wall of the model, the difference exceeded $10 \%$. The removal of systematic uncertainties, such as cone misalignment, in future measurements will improve the comparison.

Finally, boundary-layer surveys were performed downstream of a single diamond-shaped roughness element that was placed on the cone model. For the results presented in this paper, the surveys were confined to the centerline ray emanating from the roughness element. The mean-flow measurements imply a low-speed streak trailing the roughness element and a shear-layer region, lying several trip heights away from the wall, was identified. That shear layer appears to support a band of unstable frequencies, peaking in the 150-250 $\mathrm{kHz}$ range, that grow exponentially in the downstream direction until they saturate and then asymptotically 
decay as the flow evolves towards a turbulent state.

In view of the boundary-layer measurements presented in this paper, we are confident that the same techniques will be applicable to the flat-plate model tests in the SLDT. Forthcoming experimental work in this research effort will focus on the flat-plate model, and there, we will consider flow conditions and roughness geometries that match those used in the computational simulations by Choudhari, et al. Measurements in the laminar boundary layer on the flat plate and measurements of the roughness-induced instabilities will be performed. If the measurements confirm the role played by streak instabilities in roughness-induced transition, then a physics-based $N$-factor correlation may be developed.

\section{Acknowledgements}

This work was performed as part of the Aerodynamics, Aerothermodynamics, and Plasma Dynamics (AAP) discipline of the Hypersonics Project and the Supersonic Cruise Efficiency discipline of the Supersonics Project-both of which are under NASA's Fundamental Aeronautics Program (FAP). The Associate Principal Investigators of those respective disciplines, Deepak Bose and Linda Bangert, are thanked for their support. The authors thank the members of our high-speed research group in the Flow Physics and Control Branch for their many useful discussions throughout the test program and assistance in the development of test hardware: George Beeler, Frank Chen, Steve Wilkinson, Ponnampalam Balakumar, and Catherine McGinley. The authors thank P. Balakumar for the mean-flow computations over the cone model. Mark Cagle, Chris Laws, and Sandy Webb are to be recognized for the design of the flat plate and cone models used in this study. Mark Roth, Tom Hall, and Wayne Geouge are recognized for their truly professional craftsmanship and innovative ideas related to the assembly of the hot-wire probes and pitot probes. Finally, the authors thank our facility technicians: Hugh Pinkston, Rhonda Mills, and Ricky Clark, and personnel in the air-support group, for wind-tunnel operations.

\section{References}

\footnotetext{
${ }^{1}$ McGinley, C. B., Berry, S. A., Kinder, G. R., Barnwell, M., Wang, K. C., and Kirk, B. S., "Review of Orbiter Flight Boundary Layer Transition Data," AIAA Paper 2006-2921, June 2006.

${ }^{2}$ Berry, S. A., Horvath, T. J., Cassady, A. M., Kirk, B. K., Wang, K., and Hyatt, A. J., "Boundary Layer Transition Results from STS-114," AIAA Paper 2006-2922, June 2006.

${ }^{3}$ Berry, S. A., Auslender, A. H., Dilley, A. D., and Calleja, J. F., "Hypersonic Boundary-Layer Trip Development for Hyper-X," Journal of Spacecraft and Rockets, Vol. 38, No. 6, November-December 2001, pp. 853-864.

${ }^{4}$ Berry, S. A. and Horvath, T. J., "Discrete-Roughness Transition for Hypersonic Flight Vehicles," Journal of Spacecraft and Rockets, Vol. 45, No. 2, March-April 2008, pp. 216-227.

${ }^{5}$ Reda, D. C., "Review and Synthesis of Roughness-Dominated Transition Correlations for Reentry Applications," Journal of Spacecraft and Rockets, Vol. 39, No. 2, March-April 2002, pp. 161-167.

${ }^{6}$ Beckwith, I. E. and Miller, C. G., "Aerothermodynamics and Transition in High-Speed Wind Tunnels at NASA Langley," Annual Review of Fluid Mechanics, Vol. 22, 1990, pp. 419-439.

${ }^{7}$ Casper, K. M., Wheaton, B. M., Johnson, H. B., and Schneider, S. P., "Effect of Freestream Noise on Roughness-Induced Transition at Mach 6," AIAA Paper 2008-4291, June 2008.

${ }^{8}$ Borg, M. P., Schneider, S. P., and Juliano, T. J., "Effect of Freestream Noise on Roughness-Induced Transition for the X-51A Forebody," AIAA Paper 2008-0592, January 2008.

${ }^{9}$ Wheaton, B. M., Roughness-Induced Instability in a Laminar Boundary Layer at Mach 6, Master's thesis, Purdue University, West Lafayette, Indiana, December 2009.

${ }^{10}$ Choudhari, M., Li, F., Wu, M., Chang, C., Edwards, J., Kegerise, M., and King, R., "Laminar-Turbulent Transition behind Discrete Roughness Elements in a High-Speed Boundary Layer," AIAA Paper 2010-1575, January 2010.

${ }^{11}$ Beckwith, I. E., Creel, T. R., Chen, F.-J., and Kendall, J. M., "Free-Stream Noise and Transition Measurements on a Cone in a Mach 3.5 Pilot Low-Disturbance Tunnel," NASA TP 2180, September 1983.

${ }^{12}$ Chen, F.-J., "Boundary-Layer Transition Extent Measurements on a Cone and Flat Plate at Mach 3.5," AIAA Paper 93-0342, January 1993.

${ }^{13}$ Laufer, J., "Aerodynamic Noise in Supersonic Wind Tunnels," Journal of the Aerospace Sciences, Vol. 28, No. 9, September 1961, pp. 685-692.

${ }^{14}$ Anders, J. B., Stainback, P. C., and Beckwith, I. E., "New Technique for Reducing Test Section Noise in Supersonic Wind Tunnels," AIAA Journal, Vol. 18, No. 1, January 1980, pp. 5-6.

${ }^{15}$ Chen, F.-J., Malik, M. R., and Beckwith, I. E., "Advanced Mach 3.5 Axisymmetric Quiet Nozzle," AIAA Paper 90-1592, June 1990.

${ }^{16}$ Owens, L. R., Kegerise, M. A., and Wilkinson, S. P., "Off-Body Boundary-Layer Measurement Techniques Development for Supersonic Low-Disturbance Flows," Extended abstract submitted for the 49th AIAA Aerospace Sciences Meeting, January 2011.
} 
${ }^{17}$ Matlis, E. H., Controlled Experiments on Instabilities and Transition to Turbulence on Sharp Cones at Supersonic Mach Numbers, Ph.D. thesis, University of Notre Dame, Notre Dame, IN, September 2003.

${ }^{18}$ Owens, L. R. and Kegerise, M. A., "Computational and Experimental Investigation of Probe Interaction with a Flat-Plate Supersonic Laminar Boundary-Layer Flow," NASA TP in preparation.

${ }^{19}$ Freymuth, P., "Noise in Hot-Wire Anemometers," The Review of Scientific Instruments, Vol. 39, No. 4, April 1968, pp. 550-557.

${ }^{20}$ Smits, A. J., Hayakawa, K., and Muck, K. C., "Constant Temperature Hot-Wire Anemometer Practice in Supersonic Flows, Part 1: The Normal Wire," Experiments in Fluids, Vol. 1, 1983, pp. 83-92.

${ }^{21}$ Jones, G., "Wind Tunnel Requirements for Hot-Wire Calibration," AIAA Paper 94-2534, June 1994.

${ }^{22}$ Laufer, J. and McClellan, R., "Measurements of heat transfer from fine wires in supersonic flows," Journal of Fluid Mechanics, Vol. 1, January 1956, pp. 276-289.

${ }^{23}$ Kovasznay, L. S., "The Hot-Wire Anemometer in Supersonic Flow," Journal of the Aeronautical Sciences, Vol. 17, No. 9, September 1950, pp. 565-572.

${ }^{24}$ Balakumar, P. and Kegerise, M., "Receptivity of Hypersonic Boundary Layers over Straight and Flared Cones," AIAA Paper 2010-1065, January 2010.

${ }^{25}$ Kendall, J., An Experimental Investigation of Leading-Edge Shock-Wave-Boundary-Layer Interaction at Mach 5.8, Ph.D. thesis, California Institute of Technology, Pasadena, CA, 1956. 